\title{
File Compression and Expansion of the Genetic Code by the Use of the Yin/Yang Directions to Find its Sphered Cube
}

\section{Fernando Castro Chavez}

Department of Medicine, Atherosclerosis and Vascular Medicine Section, Baylor College of Medicine, Houston, TX, USA

\begin{abstract}
Objective: The objective of this article is to demonstrate that the genetic code can be studied and represented in a 3-D Sphered Cube for bioinformatics and for education by using the graphical help of the ancient "Book of Changes" or I Ching for the comparison, pair by pair, of the three basic characteristics of nucleotides: H-bonds, molecular structure, and their tautomerism.

Methods: The source of natural biodiversity is the high plasticity of the genetic code, analyzable with a reverse engineering of its 2-D and 3-D representations (here illustrated), but also through the classical 64-hexagrams of the ancient I Ching, as if they were the 64-codons or words of the genetic code.

Results: In this article, the four elements of the Yin/Yang were found by correlating the $3 \times 2=6$ sets of Cartesian comparisons of the mentioned properties of nucleic acids, to the directionality of their resulting blocks of codons grouped according to their resulting amino acids and/or functions, integrating a 384 codon Sphered Cube whose function is illustrated by comparing six brain peptides and a promoter of osteoblasts from Humans versus Neanderthal, as well as to Negadi's work on the importance of the number 384 within the genetic code.

Conclusions: Starting with the codon/anticodon correlation of Nirenberg, published in full here for the first time, and by studying the genetic code and its 3-D display, the buffers of reiteration within codons codifying for the same amino acid, displayed the two long (binary number one) and older Yin/Yang arrows that travel in opposite directions, mimicking the parental DNA strands, while annealing to the two younger and broken (binary number zero) Yin/Yang arrows, mimicking the new DNA strands; the graphic analysis of the genetic code and its plasticity was helpful to compare compatible sequences, while further exploring the wondrous biodiversity of nature for educational purposes.
\end{abstract}

Keywords: Genetic code; I Ching; Cube; Sphered cube; Cubed sphere; Yin and yang; Bioinformatics

\section{Abbrevations:}

\section{Introduction}

When studying the genetic code, the first question to ask could be: "What is a 'code'?" The most obvious answer is that a code is a set of correspondences between two different languages. In the same way, the bioinformatics context of this article is an interface between the geometry within bioinformatics and its cryptography [1].

For example, let's remember the intuitive letter-to-number code of our childhood (evocative of the Roman numerals that lacked of zero), also called the "letter number" cipher or code, in which the letters of an alphabet are replaced by numbers in their respective order: transforming abc... into $1-2-3 \ldots{ }^{1}$

A more counter-intuitive variant of such letter-to-number code is the one that includes the zero (0) at the start (as did the Arabic numerical system, now in worldwide use, even in programming, a system that apparently was developed independently by the Mayans); starting with abc..., which in this new code that includes the zero, is transformed into $0-1-2 \ldots$, ending with ...xyz being translated into ...23-24-25 [1]; and, even the fingers of both of our hands can be used in mnemonics in

1http://web.archive.org/web/20101129051637/http://rumkin.com/tools/cipher/ numbers.php

${ }^{2}$ Abbr.: Amino acids: A: alanine (Ala), V: valine (Val), I: isoleucine (lle), L: leucine (Leu), M: methionine (Met), F: phenylalanine (Phe), W: tryptophan (Trp), D: aspartic acid (Asp), N: asparagine (Asn), E: glutamic acid (Glu), Q: glutamine (Gln), R: arginine (Arg), K: lysine (Lys), S: serine (Ser), T: threonine (Thr), G: glycine (Gly), P: proline (Pro), H: histidine (His), C: cysteine (Cys), Y: tyrosine (Tyr). Nucleotides (nt): U: uracil, C: cytosine, A: adenine, G: guanine, T: thymine. $n$ : any $n t$, $r$ : purines, $y$ : pyrimidines. order to remember this code, and by analogy, to remember the genetic code; furthermore, our four extremities can be used to remember its four foundational nucleotides $(\mathrm{A}, \mathrm{T}, \mathrm{C}, \mathrm{G})^{2}$ for a better understanding of the bio-flexibility of the genetic code.

Thus far, these are the basic aspects on the study of the genetic code, aspects relatively easy to remember by a student exposed for the first time to it; but we are going to find here additional tools that can be used, not only in education, but also in bioinformatics, for the more deeply appreciation of the source of information contained within the genetic code. For the basic computational concept of file compression, we read: "File compression reduces the size of a file by cleverly taking out parts of the contents of the file that aren't needed... Zipping is very common, particularly because it reduces the amount of data that needs to be transported from here to there" [2].

We need to start with the unpublished and handwritten representation of the set of 64 codons done by Nirenberg in 1965 [3] (shown in Table 1; published in full as a primer in this article). After

*Corresponding author: Fernando Castro Chavez, Department of Medicine, Atherosclerosis and Vascular Medicine Section, Baylor College of Medicine, Houston, TX, USA, Tel: +1 713798 4177; Fax: 713-798-4121; E-mail: fdocc@yahoo.com

\section{Received March 04, 2014; Accepted May 20, 2014; Published June 05, 2014}

Citation: Castro-Chavez F (2014) File Compression and Expansion of the Genetic Code by the Use of the Yin/Yang Directions to Find its Sphered Cube. J Biodivers Biopros Dev 1: 112. doi:10.4172/2376-0214.1000112

Copyright: (c) 2014 Castro-Chavez F. This is an open-access article distributed under the terms of the Creative Commons Attribution License, which permits unrestricted use, distribution, and reproduction in any medium, provided the original author and source are credited. 


\begin{tabular}{|c|c|c|c|c|c|}
\hline & & 1 & 2 & 3 & 4 \\
\hline & & U & C & A & G \\
\hline 1 & UU & $\begin{array}{c}5^{\prime}-U U U=F \\
A A A-5^{\prime}\end{array}$ & $\begin{array}{c}5^{\prime}-U \cup C=F \\
A A G-5^{\prime}\end{array}$ & $\begin{array}{c}5^{\prime}-U U A=L \\
A A U-5^{\prime}\end{array}$ & $\begin{array}{c}5^{\prime}-U U G=L \\
A A C-5^{\prime}\end{array}$ \\
\hline 2 & UC & $\begin{array}{c}5^{\prime}-U C U=S \\
A G A-5^{\prime}\end{array}$ & $\begin{array}{c}5^{\prime}-U C C=S \\
A G G-5^{\prime}\end{array}$ & $\begin{array}{c}5^{\prime}-U C A=S \\
A G U-5\end{array}$ & $\begin{array}{c}5,-U C G=S \\
A G C-5,\end{array}$ \\
\hline 3 & UA & $\begin{array}{c}5^{\prime}-\cup A U=Y \\
A \cup A-5^{\prime}\end{array}$ & $\begin{array}{c}5^{\prime}-U A C=Y \\
A \cup G-5,\end{array}$ & $\begin{array}{c}5^{\prime}-U A A={ }^{*} \\
\quad A \cup U-5^{\prime}\end{array}$ & $\begin{array}{c}5^{\prime}-U A G={ }^{*} \\
\quad A \cup C-5^{\prime}\end{array}$ \\
\hline 4 & UG & $\begin{array}{c}5^{\prime}-U G U=C \\
A C A-5^{\prime}\end{array}$ & $\begin{array}{c}5^{\prime}-U G C=C \\
A C G-5,\end{array}$ & $\begin{array}{c}5 \cdot-U G A={ }^{\prime} \\
A C U-5\end{array}$ & $\begin{array}{c}5^{\prime}-U G G=W \\
A C C-5^{\prime}\end{array}$ \\
\hline 5 & CU & $\begin{array}{c}5^{\prime}-C U U=L \\
G A A-5^{\prime}\end{array}$ & $\begin{array}{c}5^{\prime}-C U C=L \\
G A G-5^{\prime}\end{array}$ & $\begin{array}{c}5^{\prime}-C U A=L \\
G A U-5\end{array}$ & $\begin{array}{c}5^{\prime}-C U G=L \\
G A C-5,\end{array}$ \\
\hline 6 & CC & $\begin{array}{c}5^{\prime}-C C U=P \\
G G A-5^{\prime}\end{array}$ & $\begin{array}{c}5^{\prime}-C C C=P \\
G G G-5\end{array}$ & $\begin{array}{c}5^{\prime}-C C A=P \\
G G U-5\end{array}$ & $\begin{array}{c}5^{\prime}-C C G=P \\
G G C-5,\end{array}$ \\
\hline 7 & CA & $\begin{array}{c}5^{\prime}-\mathrm{CAU}=\mathrm{H} \\
G U A-5^{\prime}\end{array}$ & $\begin{array}{c}5^{\prime}-C A C=H \\
G \cup G-5\end{array}$ & $\begin{array}{c}5^{\prime}-C A A=Q \\
G U U-5^{\prime}\end{array}$ & $\begin{array}{c}5^{\prime}-C A G=Q \\
G U C-5,\end{array}$ \\
\hline 8 & CG & $\begin{array}{c}5^{\prime}-C G U=R \\
G C A-5^{\prime}\end{array}$ & $\begin{array}{c}5^{\prime}-C G C=R \\
G C G-5^{\prime}\end{array}$ & $\begin{array}{c}5^{\prime}-\mathrm{CGA}=R \\
G C U-5^{\prime}\end{array}$ & $\begin{array}{c}5^{\prime}-C G G=R \\
G C C-5,\end{array}$ \\
\hline 9 & $\mathrm{AU}$ & $\begin{array}{c}5^{\prime}-A U U=I \\
U A A-5^{\prime}\end{array}$ & $\begin{array}{c}5^{\prime}-A U C=I \\
U A G-5\end{array}$ & $\begin{array}{c}5^{\prime}-A U A=I \\
U A U-5^{\prime}\end{array}$ & $\begin{array}{c}5^{\prime}-\mathrm{AUG}=M \\
U A C-5^{\prime}\end{array}$ \\
\hline 10 & AC & $\begin{array}{c}5^{\prime}-A C U=T \\
U G A-5^{\prime}\end{array}$ & $\begin{array}{c}5^{\prime}-A C C=T \\
U G G-5\end{array}$ & $\begin{array}{c}5^{\prime}-\mathrm{ACA}=\boldsymbol{T} \\
U G U-5\end{array}$ & $\begin{array}{c}5^{\prime}-\mathrm{ACG}=T \\
U G C-5^{\prime}\end{array}$ \\
\hline 11 & AA & $\begin{array}{c}5^{\prime}-A A U=\mathbf{N} \\
U \cup A-5^{\prime}\end{array}$ & $\begin{array}{c}5^{\prime}-\mathrm{AAC}=\boldsymbol{N} \\
U \cup G-5^{\prime}\end{array}$ & $\begin{array}{c}5^{\prime}-\mathrm{AAA}=K \\
\quad U \cup U-5\end{array}$ & $\begin{array}{c}5^{\prime}-\mathrm{AAG}=K \\
U \cup C-5^{\prime}\end{array}$ \\
\hline 12 & AG & $\begin{array}{c}5^{\prime}-A G U=S \\
U C A-5^{\prime}\end{array}$ & $\begin{array}{c}5^{\prime}-A G C=S \\
U C G-5\end{array}$ & $\begin{array}{c}5^{\prime}-\mathrm{AGA}=R \\
U C U-5^{\prime}\end{array}$ & $\begin{array}{c}5^{\prime}-\mathrm{AGG}=R \\
U C C-5^{\prime}\end{array}$ \\
\hline 13 & GU & $\begin{array}{c}5^{\prime}-\mathrm{GUU}=\boldsymbol{V} \\
C A A-5^{\prime}\end{array}$ & $\begin{array}{c}5^{\prime}-G U C=V \\
C A G-5,\end{array}$ & $\begin{array}{c}5^{\prime}-G U A=V \\
C A U-5\end{array}$ & $\begin{array}{c}5^{\prime}-G U G=V \\
C A C-5,\end{array}$ \\
\hline 14 & GC & $\begin{array}{c}5^{\prime}-G C U=A \\
C G A-5^{\prime}\end{array}$ & $\begin{array}{c}5^{\prime}-G C C=A \\
C G G-5{ }^{\prime}\end{array}$ & $\begin{array}{c}5^{\prime}-G C A=A \\
C G U-5,\end{array}$ & $\begin{array}{c}5^{\prime}-G C G=A \\
C G C-5,\end{array}$ \\
\hline 15 & GA & $\begin{array}{c}5^{\prime}-\mathrm{GAU}=\boldsymbol{D} \\
C U A-5^{\prime}\end{array}$ & $\begin{array}{c}5^{\prime}-\mathrm{GAC}=\mathrm{D} \\
C \cup G-5,\end{array}$ & $\begin{array}{c}5^{\prime}-\mathrm{GAA}=E \\
\quad C U U-5\end{array}$ & $\begin{array}{c}5^{\prime}-\mathrm{GAG}=E \\
C U C-5,\end{array}$ \\
\hline 16 & GG & $\begin{array}{c}5^{\prime}-\mathrm{GGU}=\mathbf{G} \\
C C A-5^{\prime}\end{array}$ & $\begin{array}{c}5^{\prime}-\mathrm{GGC}=\mathbf{G} \\
C C G-5^{\prime}\end{array}$ & $\begin{array}{c}5^{\prime}-\mathrm{GGA}=\mathbf{G} \\
C C U-5^{\prime}\end{array}$ & $\begin{array}{c}5^{\prime}-\mathrm{GGG}=\mathbf{G} \\
C C C-5,\end{array}$ \\
\hline
\end{tabular}

Table 1: Nirenberg's first $16 \times 4=64$ codon/anticodon table (shown here for the first time in its complete form), being the codons with their anti-sense complements reordered according to the now-classical sequence of $U, C, A, G[4,5]$, from top to bottom, and from left to right; in bold italics their corresponding amino acids; also shown, the direction of the start, or 5'- from left-to-right for the codons that codify in the upper lines, and from -5 , from right-to-left for the non-coding codons in the lower lines below the previous ones; this table has been modified from [3]: Here, the columns of the $x$ axis have been numbered.

the representation of Nirenberg (Table 1), the table of Crick arrived in 1967 [4], then the circular representation by Bresch and Hausmann in 1972 [5], and then Fujimoto's tetrahedron in 1987 [6], being the last one similar to a backbone developed by Kepler many years before [7]; then, a set of more recent rules of variation $[8,9]$ was discovered while carefully analyzing [5], plus newer representations, including the use of the I Ching [10], the tetrahedron [11], and the rotating square [12], among others.

Efforts have been done to represent the genetic code in a binary way independent of the I Ching [13]; however, the I Ching is useful for the study the genetic code and was previously compared to a detailed treatment of Nirenberg's Table in order to obtain quasi-symmetrical representations of chromosomes [10]. Likewise, in a similar fashion that the currently known letters of the genetic code are represented by AGTC, the first Hebrew mention of the genetic code ${ }^{3}$ uses four letters (grouped in $2 \times 2$ ), exactly as it happens in real life: being the four letters of the genetic code grouped by threes to produce $4 \times 4 \times 4=64$ codons or words of exactly the same length per codon (three letters).

Now, the purpose of a teacher of the genetic code is to make

${ }^{3}$ Psalm 139:16, http://biblehub.com/interlinear/psalms/139-16.htm. it known by illustrating its extremely intelligent design and its complexities in the simplest way as possible; however, most of the current text books spend only one page representing the genetic code via Crick's 'square' representation [4]. The word 'genetic' can be defined as: 'the biological information that specifies the characteristics and metabolism of an organism. The information in most of the biological life on earth is contained inside the nowfamous double helix [14] that swirls like in a 'fusion dance', tightly packaged within the chromosomes inside the nucleus of each living cell, except for the red blood cells that, by design, expel their nucleus, transforming themselves into biological 'automatons', or 'robots', for the cellular exchange between oxygen and $\mathrm{CO}_{2}$.

The genetic information that is transcribed from DNA to RNA in the nucleus is translated into proteins in the cellular cytoplasm, ending forming, these proteins, the structures and metabolism of our bodies.

The basic units that contain the information for our proteins are called 'genes', with each gene being composed of multiple nucleotides. The modular structure of the genes integrated by exons depicts the potential of a gene to produce several proteins through the cut-andpaste' (splicing) mechanism.

The words of the genetic code are the groups of three nucleotides called codons, producing the proteins that are formed by different combinations of the 20 amino acids, with some of those combinations being so frequent that these popular groups of amino acids, or of peptides, are considered as 'domains'.

Next, the reverse-engineered Figures 1 and 2 are the square and the circular representations, respectively, of a functional tetrahedron discovered earlier [11] as a representation of the genetic code.

The periodicities or rotational correspondences of these representations of the genetic code are clearly identifiable when we rotate the quadrants by 90 degrees, keeping a positional and prominent correspondence for most of the essential hydrophobic amino acids located at the centre of the square of Figure 1 [12], remaining at the

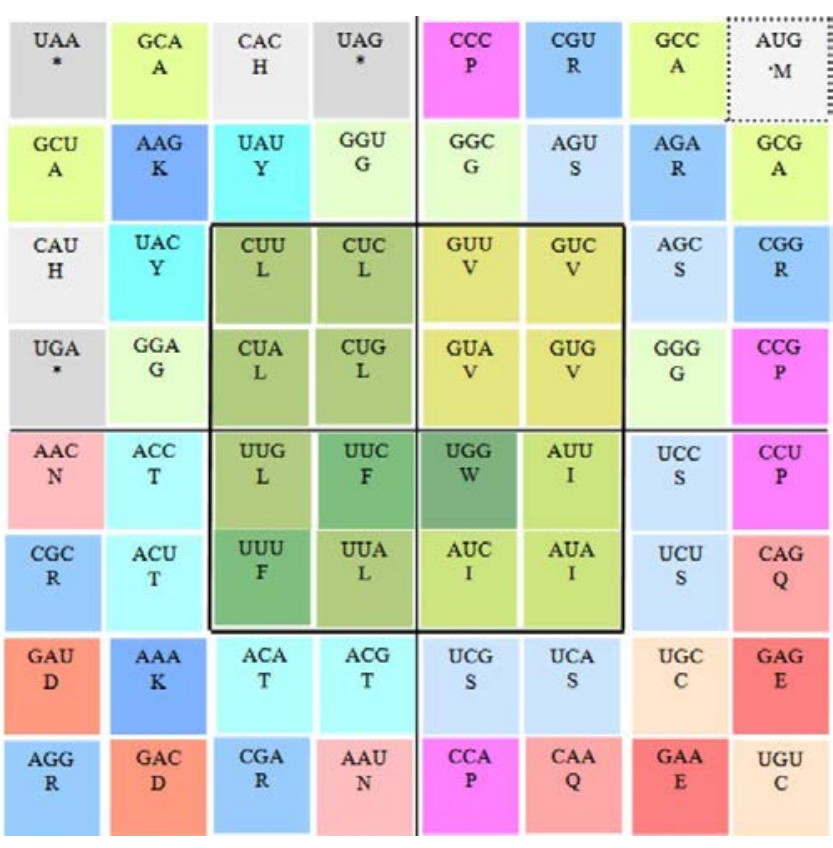

Figure 1: $8 \times 8=64$ square representation of the functional $3-D$ tetrahedron genetic code [11] 
Citation: Castro-Chavez F (2014) File Compression and Expansion of the Genetic Code by the Use of the Yin/Yang Directions to Find its Sphered Cube. J Biodivers Biopros Dev 1: 112. doi:10.4172/2376-0214.1000112

Page 3 of 17

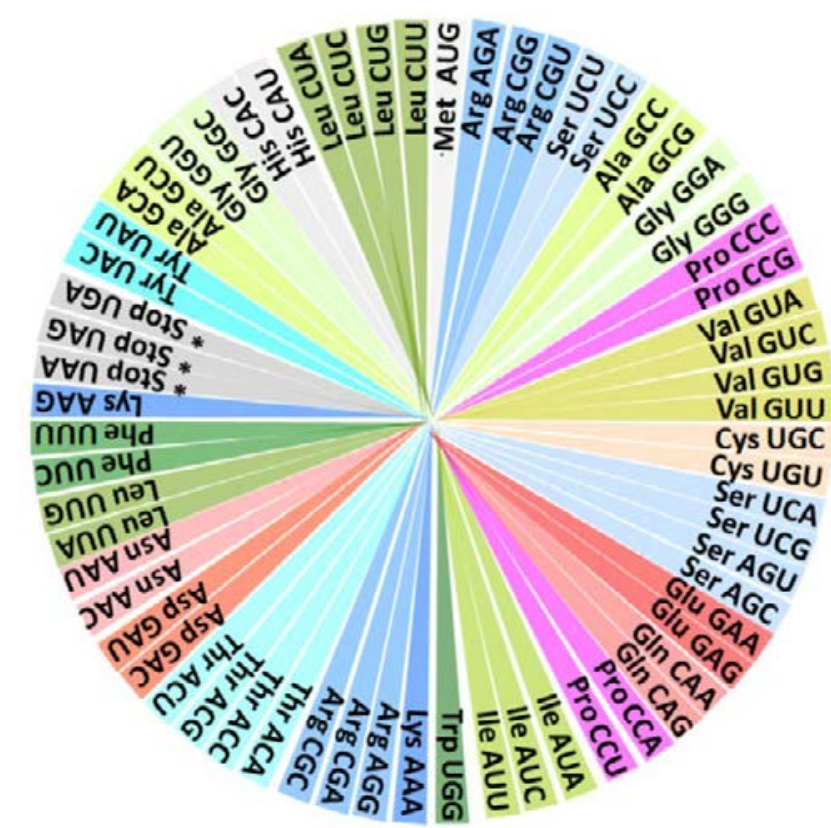

Figure 2: Circular representation of the functional $16 \times 4=64,3-D$ tetrahedral genetic code [11].

Also, and in order to detail the representation of the genetic code introduced in [10], the folded and 'compressed' 3-D representation of a double tetrahedron can be seen in Figures 3 and 4: being one functional and the other a 100\% symmetrical geometry (with its Stella Octangula net shown in [10]).
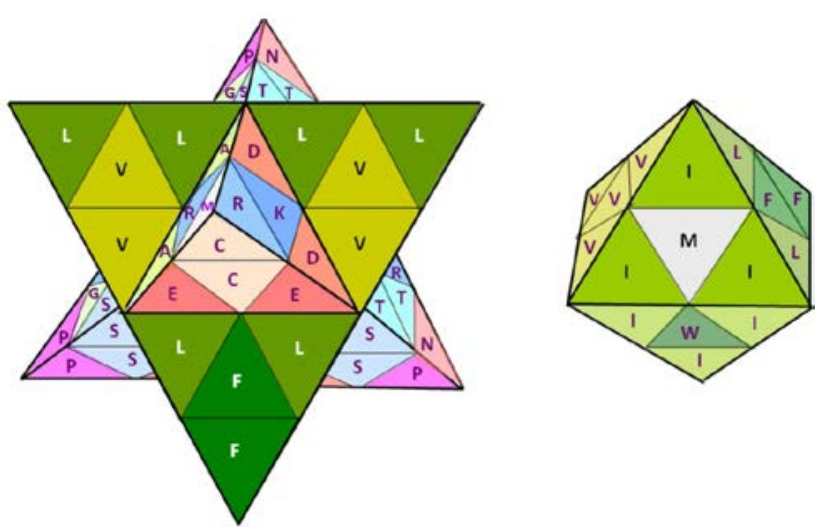

Figure 3: Stella Octangula viewed from the top; its original codon pattern was shown in [10].

same relative rotational position in the circle shown in Figure $2[8,9]$.

Also, and in order to detail the representation of the genetic code introduced in [10], the folded and 'compressed' 3-D representation of a double tetrahedron can be seen in Figures 3 and 4: being one functional and the other a $100 \%$ symmetrical geometry (with its Stella Octangula net shown in [10]).

The double genetic code was 'physically' compressed as represented in Figures 3 and 4, indicating that through the 3-D geometry of a Stella Octangula it's possible to distinguish between the start amino acid Methionine, and the non-start Methionine [10].

A complex aspect of the genetic code thus far explored is the binary correlation between the three Cartesian combinations of nucleotides (hydrogen bonds, rings, and tautomerism) by using the millenary classical or original table of the I Ching [10], shown here compressed by groups in Figures 5 and 6.

\section{Methods}

We saw in the introduction the folded Stella Octangula, as well as its inner geometries derived from the computational analogy of the file compression or zipping; however, we are interested here in its expansion through the binary I Ching representation, to obtain, not only a cubical macro representation of the genetic code, integrated by $64 \times 6=384$ codons, but also its corresponding Sphered-Cube, a resemblance of the Cubed-Sphere widely used in Mathematics, Climatology, Geology, and Astronomy. The practical purpose of this is two-fold: First, to provide educational mnemonic devices; and second, to provide a useful core for molecular modeling in bioinformatics through a, not only highly informative, but also visually aesthetic bioinformatics tool to compare
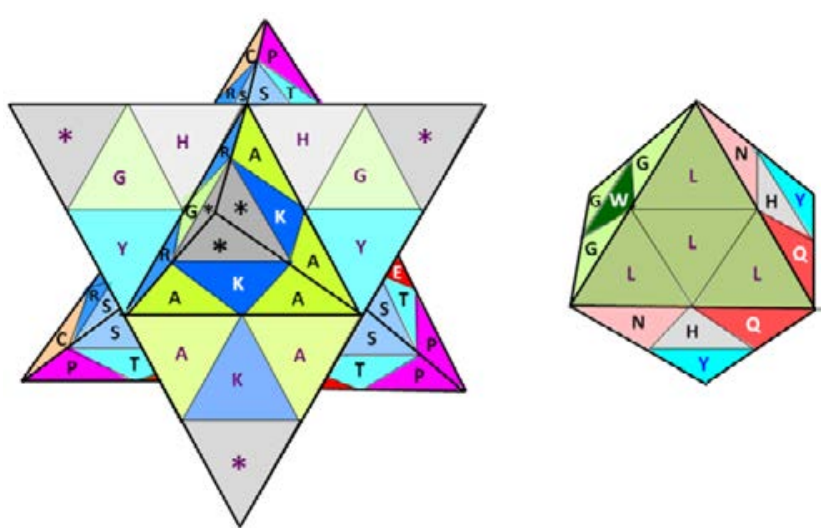

Figure 4: Stella Octangula viewed from the bottom; its original codon pattern was shown in [10]

\begin{tabular}{|c|c|c|c|c|c|c|c|c|}
\hline & 000 & 001 & 010 & 011 & 100 & 101 & 110 & 111 \\
\hline \multirow[t]{2}{*}{000} & 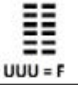 & 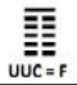 & $\begin{array}{c}\text { UCU = S } \\
\text { S }\end{array}$ & $\underset{\overline{E C C=S}}{\overline{\bar{E}}}$ & $\sum_{C U U=L}$ & $\begin{array}{c}\bar{E} \\
C U C=L\end{array}$ & $\begin{array}{c}\overline{\bar{E}} \\
C C U=P\end{array}$ & $\begin{array}{c}\underset{\bar{E}}{\bar{E}} \\
c c c=p\end{array}$ \\
\hline & 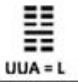 & $\underset{\substack{\bar{E} \\
U U G=L}}{\bar{E}}$ & $\begin{array}{c}\overline{\bar{X}} \\
\text { uCA }=S\end{array}$ & $\begin{array}{c}\overline{\bar{X}} \\
\text { UCG }=S\end{array}$ & $\begin{array}{c}\bar{\equiv} \\
\bar{E} \\
C U A=L\end{array}$ & $\begin{array}{c}\overline{\bar{E}} \\
\overline{C U G}=\mathrm{L}\end{array}$ & 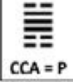 & 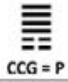 \\
\hline 001 [ & 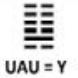 & $\begin{array}{c}\bar{E} \\
\overline{\bar{E}}=\mathbf{E}=Y\end{array}$ & $\underset{\text { UGU }}{\overline{\bar{E}}}$ & 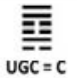 & $\begin{array}{c}\text { 动 } \\
\mathrm{CAU}=\mathrm{H}\end{array}$ & $\begin{array}{c}\overline{\bar{z}} \\
\overline{C A C}=H\end{array}$ & 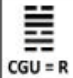 & $\underset{C G C=R}{\stackrel{\equiv}{=}}$ \\
\hline 010 & 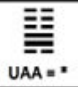 & $\begin{array}{c}\overline{\text { 王 }} \\
\text { UAG=" }\end{array}$ & $\underset{\text { UGA=. }}{\overline{\bar{E}}}$ & 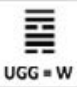 & 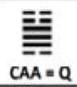 & $\begin{array}{c}\overline{\bar{\equiv}} \\
\overline{D A G}=Q\end{array}$ & $\underset{\text { CGA }=R}{\bar{\equiv}}$ & 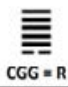 \\
\hline 011 [ & 玗 & 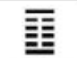 & 䞡 & $\overline{\bar{\equiv}}$ & 垩 & 至 & 立 & $\overline{\overline{\bar{x}}}$ \\
\hline \multirow[t]{2}{*}{100} & $A \cup U=1$ & $A \cup C=1$ & $A C U=T$ & $A C C=T$ & GUU $=V$ & GUC $=V$ & $G C U=A$ & $G C C=A$ \\
\hline & 玨 & 琹 & 퐆 & 玍 & 童 & 丞 & 仼 & 䇂 \\
\hline \multirow[t]{2}{*}{101} & $A \cup A=1$ & AUG $=\mathrm{M}$ & $A C A=T$ & $A C G=T$ & $\mathrm{GUA}=\mathrm{V}$ & GUG $=V$ & $G C A=A$ & $G C G=A$ \\
\hline & 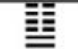 & $\overline{\bar{E}}$ & 童 & $\bar{\equiv}$ & 立 & 퐆 & 登 & $\overline{\overline{\bar{X}}}$ \\
\hline \multirow[t]{2}{*}{110} & $A A U=N$ & $A A C=N$ & $A G U=S$ & $A G C=S$ & GAU $=0$ & $G A C=0$ & $G G U=G$ & $G G C=G$ \\
\hline & 青 & 彗 & 㪯 & 聖 & 疍 & 韮 & 㪯 & 无 \\
\hline & $A A A=K$ & $A A G=K$ & $A G A=R$ & $A G G=R$ & $G A A=E$ & $G A G=E$ & $G G A=G$ & $G O B=G$ \\
\hline
\end{tabular}

Figure 5: Codons of the genetic code grouped according to the hydrogen bonding between nucleotides in the double helix in the axis $\boldsymbol{x}$, and its nucleotide rings in axis $y[10]$. 


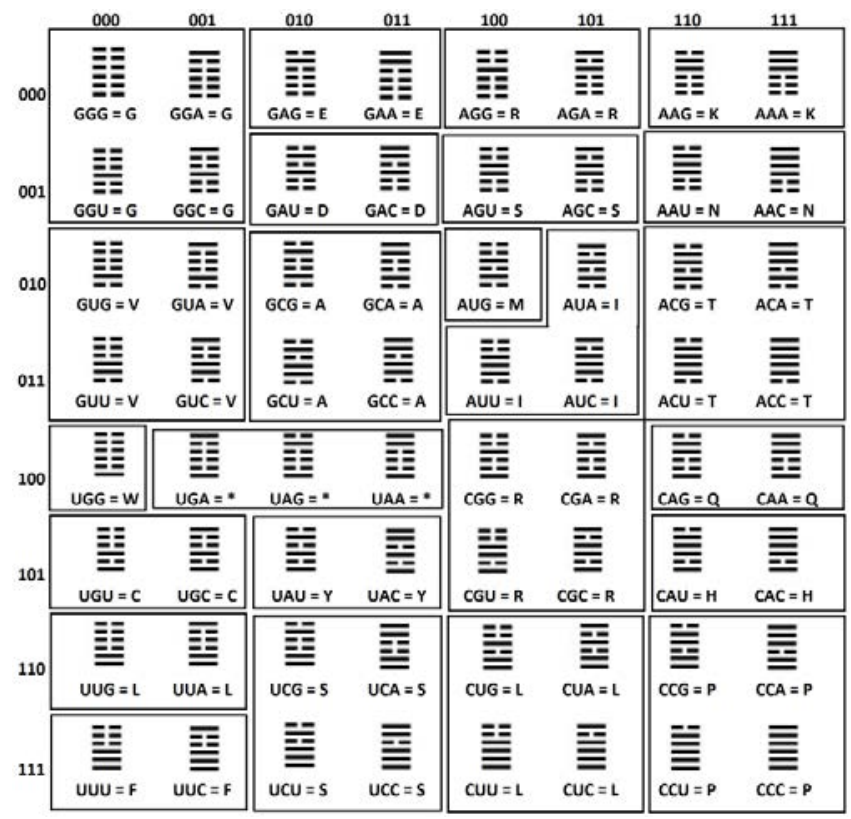

Figure 6: Codons of the genetic code by groups according to the tautomerism among nucleotides in axis $x$, and nucleotide rings in axis $y[10]$

\begin{tabular}{|c|c|c|c|}
\hline$F$ & \multirow{2}{*}{$\mathrm{s}$} & \multirow{2}{*}{ L } & \multirow{2}{*}{$P$} \\
\hline $\mathrm{L}$ & & & \\
\hline $\mathrm{Y}$ & C & $\mathrm{H}$ & \multirow{2}{*}{$\mathrm{R}$} \\
\hline$*$ & w & $\mathrm{Q}$ & \\
\hline I & \multirow[b]{2}{*}{$\mathrm{T}$} & \multirow[b]{2}{*}{$\mathrm{v}$} & \multirow[b]{2}{*}{ A } \\
\hline M & & & \\
\hline $\mathrm{N}$ & $\mathrm{s}$ & D & \multirow{2}{*}{$\mathrm{G}$} \\
\hline $\mathrm{K}$ & $\mathrm{R}$ & $\mathrm{E}$ & \\
\hline
\end{tabular}

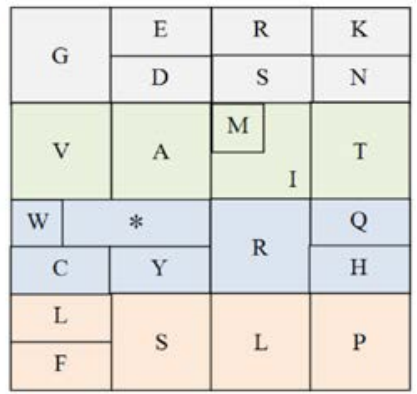

Figure 7: Groups of codons of the genetic code codifying for the same amino acid, or function; these two tables correspond, respectively: The left side to Figure 5, and the right side to Figure 6.

sequences of men and/or of other organisms; i.e., for the early detection of diseases, and/or to discover genomic compatibilities between related varieties of organisms currently misclassified as belonging to different species, or even to a different genus, instead of what they are in reality: varieties or sub-species, and vice versa. The geometries and binary structures used here are:

1) The net or pattern to obtain a folded Stella Octangula: http:// web.archive.org/web/20101124045835/http://korthalsaltes.com/ model.php?name_en=stella\%20octangula, and its hidden, internal Octahedron: http://liveweb.archive.org/http://mathworld.wolfram. com/Octahedron.html;

2) The original I Ching representation attributed to Fu-Xi: http:// liveweb.archive.org/http://www.laetusinpraesens.org/musings/images/ unknow_files/fuxi.jpg,

3) The inner cubic 3-D space for Figure 22, obtained by using the freely available software located at: http://web.archive.org/ web/20120625122500/http://www.doka.ch/Excel3Dscatterplot.htm

Figures 25 and 26 show a practical application of the genetic code's
I Ching by using both the GenBank and BlastP to compare expressed sequences and a promoter between humans and a Neanderthal, as described there.

\section{Results}

The next figures will be devoted to show the file compression and file expansion of the genetic code while advancing towards its macro representation. Figures 7 and 8 show the 'file compression', or zipping (zip), of codons according to their corresponding codified amino acids or functions.

If we now take the same groups shown in Figure 7 while removing their colours as a previous step before exhibiting their arrows that will be displaying the genetic code's Yin/Yang directionality, we obtain the Figure 8 , with its numbers and letters used here as a reference for the next step.

If we now demonstrate the directionality between the groups of codons according to their resulting amino acids or functions that are shown in Figure 8, we obtain the Yin/Yang arrows of Figure 9.

Figure 9 shows the directionality of the four basic components of the Yin/Yang as derived by the ancestral I Ching: The external arrows (flowing in opposite directions), being represented long ago by the 'Old Yin' and by the 'Old Yang' located at its extremes, while their younger and alternating pairing corresponds to the 'Young Yang' and to the 'Young Yin', respectively, being located at the centre while also moving in the opposite directions. These, in general, are also representing, both the process of DNA auto-replication (being the old strands of the double helix of DNA in the external lines, while the new strands are the internal), but also representing the process of DNA transcription into smaller segments of RNA.

If we now add the third Cartesian correlation, represented as well by the original symbols of the I Ching, we obtain what we see in Figure 10 ; and, if we go one step further and we add the arrows previously seen
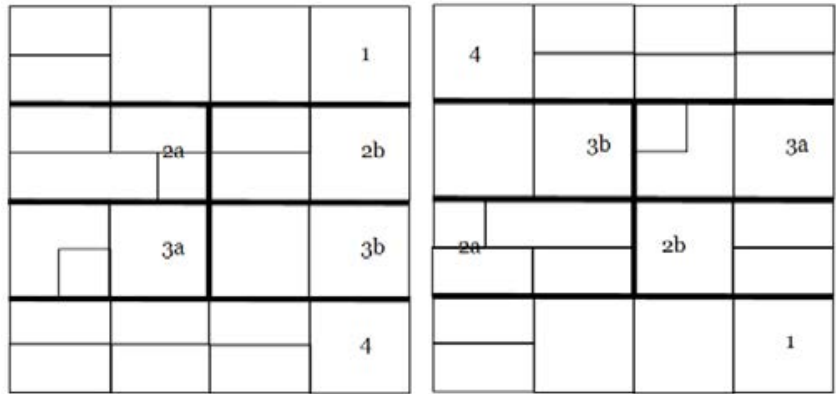

Figure 8: Numerical correspondence between the groups of codons according to their codified amino acid, or function as indicated in Figure 7.

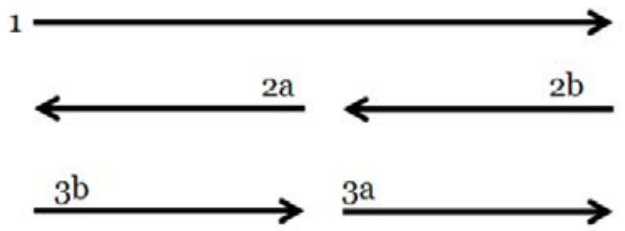

Figure 9: Arrows indicating the positional correspondence, or the 'movements', between the numbered groups within the tables shown in Figure 8 (i.e., as if the right side of Figure 8 were flipped vertically). 
Citation: Castro-Chavez F (2014) File Compression and Expansion of the Genetic Code by the Use of the Yin/Yang Directions to Find its Sphered Cube. J Biodivers Biopros Dev 1: 112. doi:10.4172/2376-0214.1000112

in Figure 9, to the cubic fusion of Figures 5, 6, and 10, such as if the first two were two contiguous walls forming an angle of 90 degrees, while the last one were the floor, just like if imagining yourself inside a cube

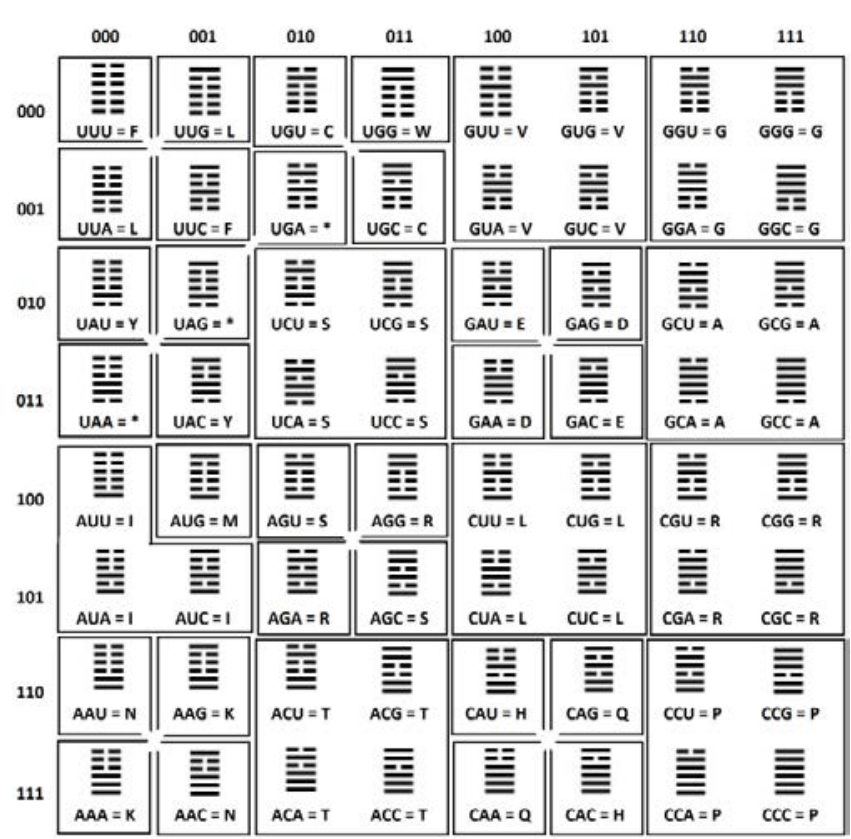

Figure 10: Codons of the genetic code by groups according to the hydrogen bonding in axis $x$, and the tautomerism among nucleotides in axis $y$, as indicated in [10] tautomerism among nucleotides in axis $y$, as indicated in [10]
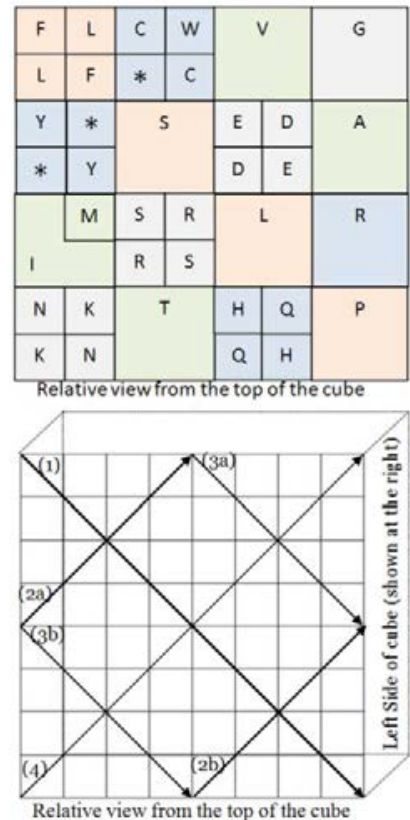

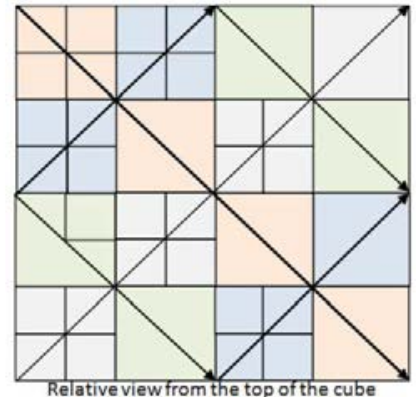

Top of cube (shown at the left side)

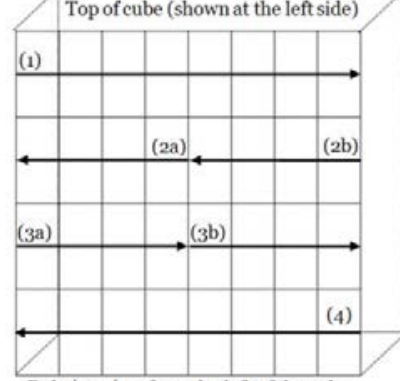

Relative view from the left of the cube

Figure 11: Relative perspective of the vector combination of the three planes previously represented in Figures 5, 6 and 10: Upper left: Geometrical location of the amino acids with the $\mathrm{H}$-bonds coordinates (axis $x: A=U=0, C=G=$ 1), paired to the tautomerism Keto/Amino coordinates (axis $y: G=U=0, A=$ $C=1$ ). Upper right: Same as the previous one, but lacking the abbreviations of amino acids while depicting its directional arrows, Figure 9. Lower left: All arrows seem to point towards the right side if seen from the top, from the front, or from the bottom. Lower right: View from 'the left side', showing the opposite directionality of each row that is present in Figure 5 when compared to Figure 6 , as indicated by Figure 9 .

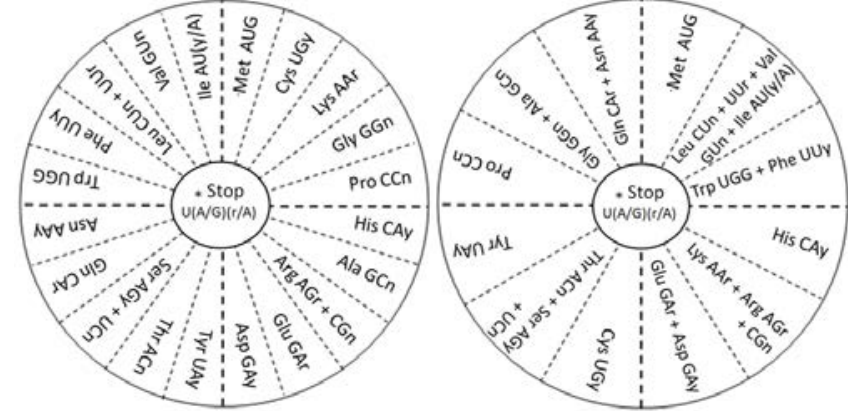

Figure 12: Two compressive possibilities to represent the genetic code within the circular configuration: Left side: A 5x4=20 circular representation of the genetic code with the stop codons shown at the center while the twenty individual amino acids and its respective codons are surrounding it. Right side A further compressed $3 \times 4=12$ representation of the genetic code also with the stop codons located at the center, and the 12 different groups of equivalent amino acids, and its respective codons, surrounding it.

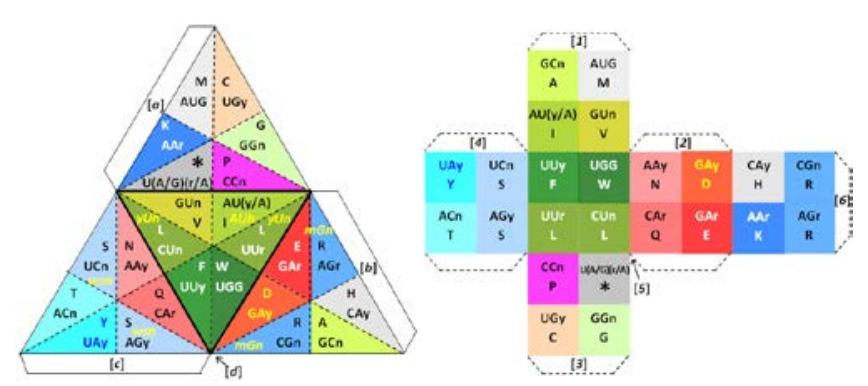

Figure 13: Two more compressive possibilities to represent the genetic code: Left side: A 6x4=24 tetrahedron net with its hydrophobic amino acids located at its bottom (center of the triangle). Right side: a $4 \times 6=24$ cube. The RGB color model, plus $25 \%$ of transparency for their amino acids is as follows: $\mathrm{P}$ : 255,0,255; R: 51,153,255; A: 204,255,51; M: 234,234,234; G: 204,255,153; S: 153,204,255; V: 204,204,0; W: 0,102,0; I: 153,204,0; Q: 255,80,80; E: 255,0,0 C: $255,204,153 ; F: 0,128,0 ;$ L: 102,153,0; T: 102,255,255; N: 255,124,128; D: 255,51,0; K: 0,102,255; Y: 0,255,255; H: 221,221,221; *: 178,178,178; color words for Y: $0,0,255$; for D: $255,255,0$. The white words had a saturated key of: $255,255,255$, while the key for the black words was the one of the absolute lack of color: $0,0,0$.

looking at two of its contiguous walls while standing on its third side, so we obtain Figure 11.

The potential for the file compression within the genetic code that we see in the preceding images can be further explored, showing here some of its numerous possibilities: In Figure 12 we see its zipped configuration in a circle while in Figure 13 we see such compression both in a tetrahedron and in a cube; these images are only some examples of the file compression applied to the genetic code analysis, which will potentially increase the speed of the analysis of sequences of DNA, RNA, or of proteins. If we now move one step further, we will be able to represent every possible binary combination of the genetic code in the classic I Ching (being only six possibilities available) within a cube, indicating that in addition to the three Cartesian correlated representations of the genetic code (in Appendixes. A we can see their common points), their three reciprocals are also included (see Appendixes. B); next, we will see the macro-representation of the genetic code in $6 \mathrm{X}$ as derived from the I Ching, either by codons (Figure 14), by amino acids (Figure 15), or by those colored codon groups that were shown before, but with no letters (Figure 16). 
Citation: Castro-Chavez F (2014) File Compression and Expansion of the Genetic Code by the Use of the Yin/Yang Directions to Find its Sphered Cube. J Biodivers Biopros Dev 1: 112. doi:10.4172/2376-0214.1000112

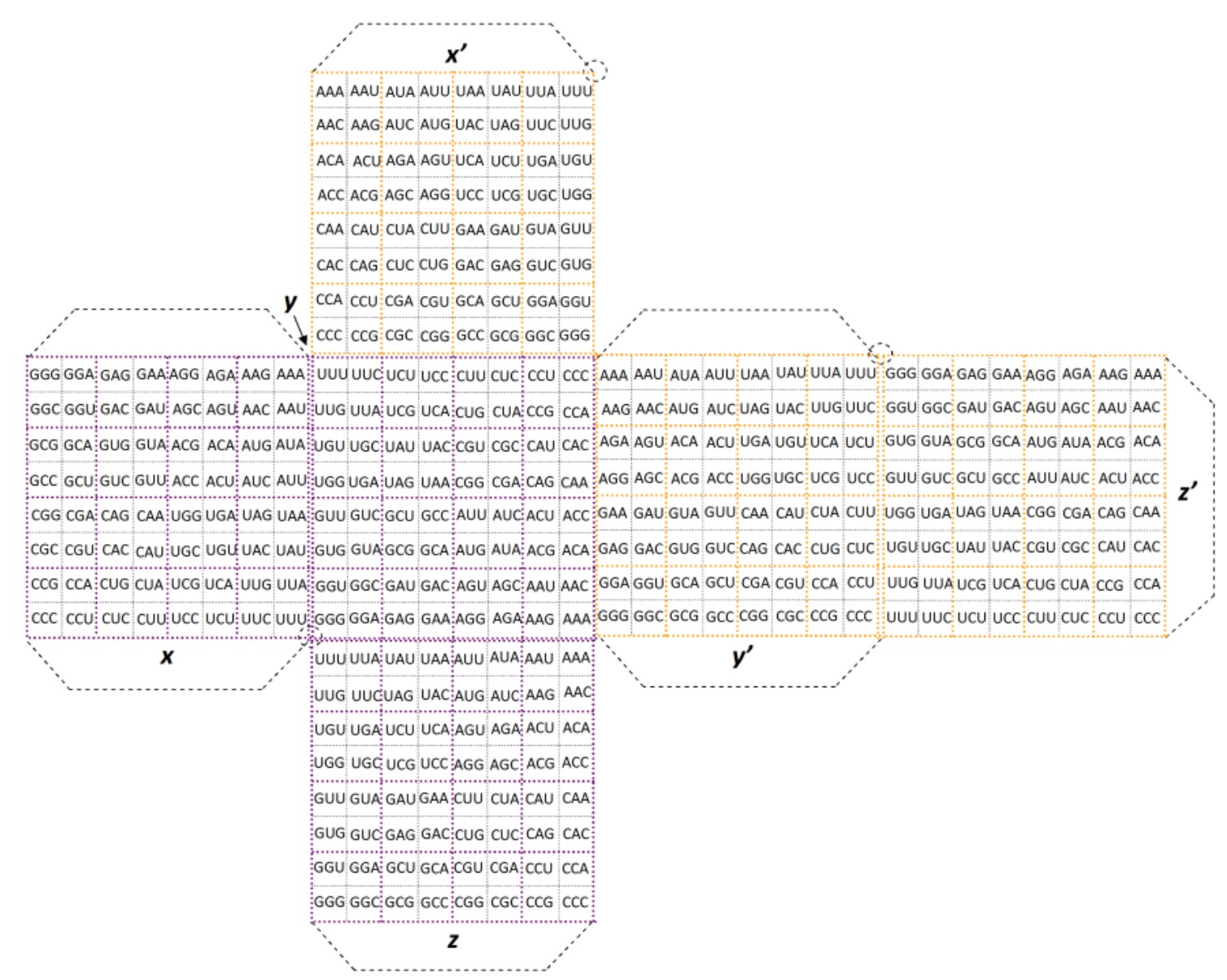

Figure 14: Net for the cubic representation of the genetic code by codons according to all possible binary correlations of their I Ching tables (see Appendix A and B, and Figures 5, 6 and 10). Dotted circles: The rotational 'poles'.

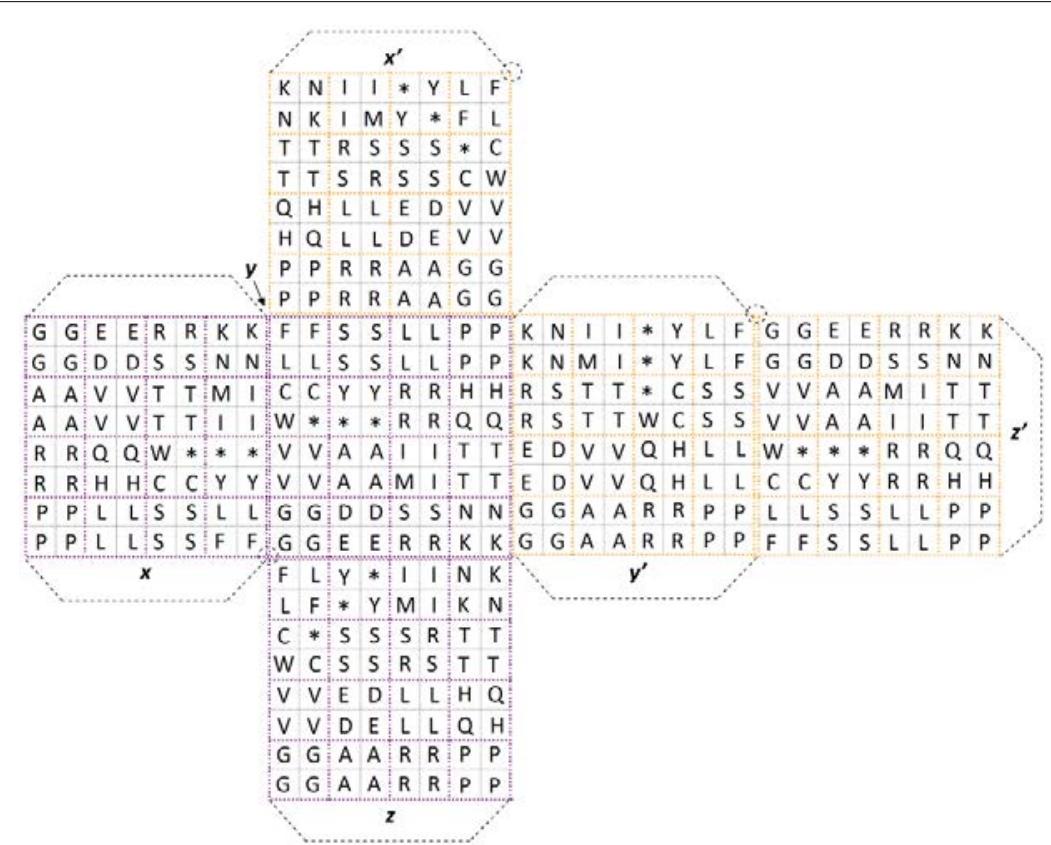

Figure 15: Pattern of the cubic representation of the genetic code by amino acids according to all possible binary I Ching correlation (see Appendix A and B and Figures 5, 6 and 10). Circles: Rotational 'poles'. 
Citation: Castro-Chavez F (2014) File Compression and Expansion of the Genetic Code by the Use of the Yin/Yang Directions to Find its Sphered Cube. J Biodivers Biopros Dev 1: 112. doi:10.4172/2376-0214.1000112

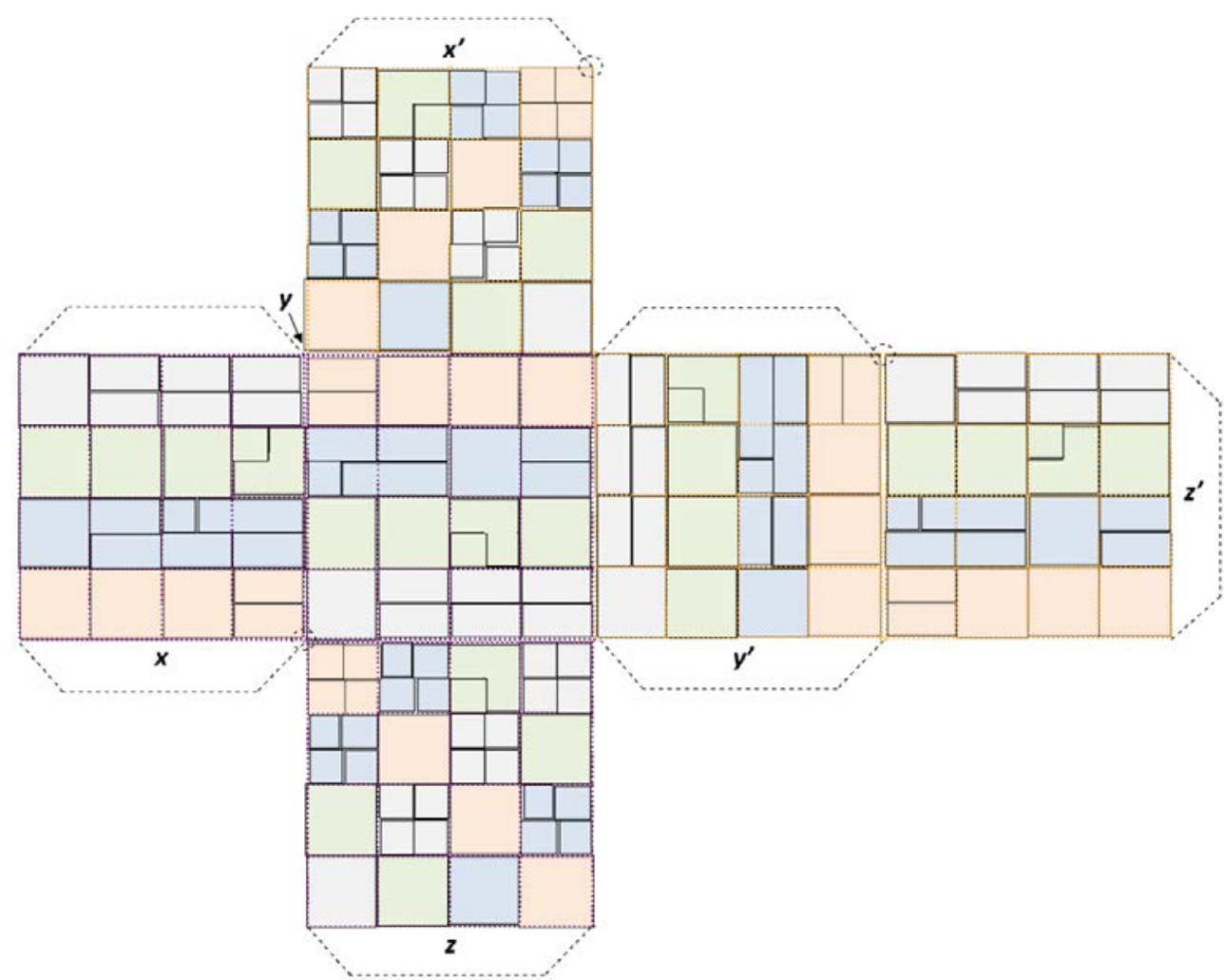

Figure 16: Pattern of the cubic representation of the genetic code by groups of codons according to its resulting amino acid, or function for all possible binary I Ching correlation (see Appendix A and B, and Figures. 5, 6 and 10). Dotted circles: Its inclined rotational 'poles' allowing a 3-faces per side visibility per rotation.

Increasing the level of complexity for our mentioned point of view as if standing inside the resulting cube, looking now to its two contiguous walls, and to its floor as if these were the three standard or normal correlations within the context shown by Figures 5,6 and 10, we have the resulting Figure 17 for the codons, and Figure 18 for their resulting amino acids.

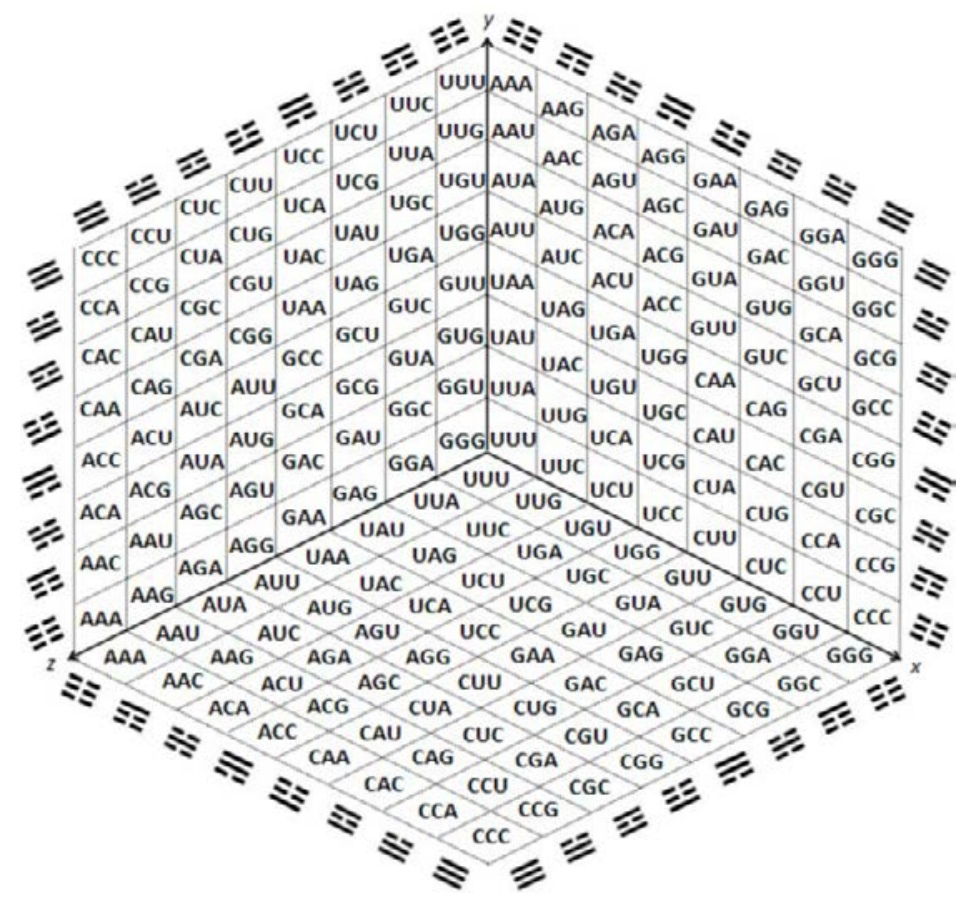

Figure 17: Inside of the three standard Cartesian / Ching binary correlations of the genetic code represented by its tables of codons as shown in Figures 5,6 , and 10 (also see Appendix A) 


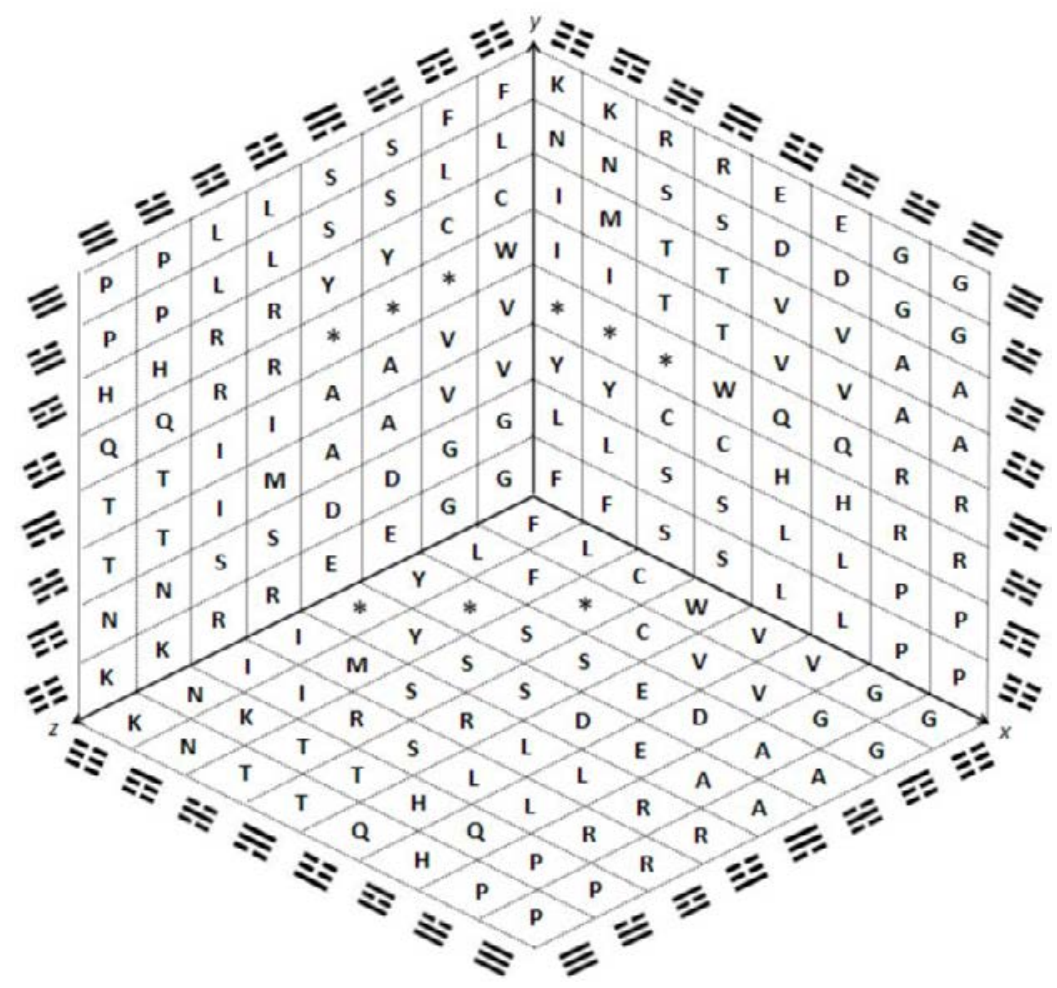

Figure 18: Inside of the three standard Cartesian I Ching binary correlations of the genetic code represented by its by amino acids as shown in Figures 5,6 , and 10 (also see Appendix A).

If we now look to the reciprocals of the previously defined as standard Cartesian I Ching genetic code correlations, we obtain Figures 19 and 20 , and Appendix B. In Appendix $C$ we see the coordinates used to obtain those standard three correlations shown in Figures 17 and 18 , as well as their respective reciprocals shown in Figures 19 and 20, within the pair of 3-D vector Cartesian graphics (axis $x, y, z$ ) contained in the cube. The final product of this article will be a Sphered Cube for the genetic code (Figures 21 and 22).

Figure 19: Inside of the three reciprocal Cartesian I Ching binary correlations of the genetic code as represented by its tables of codons (see Appendix B). 


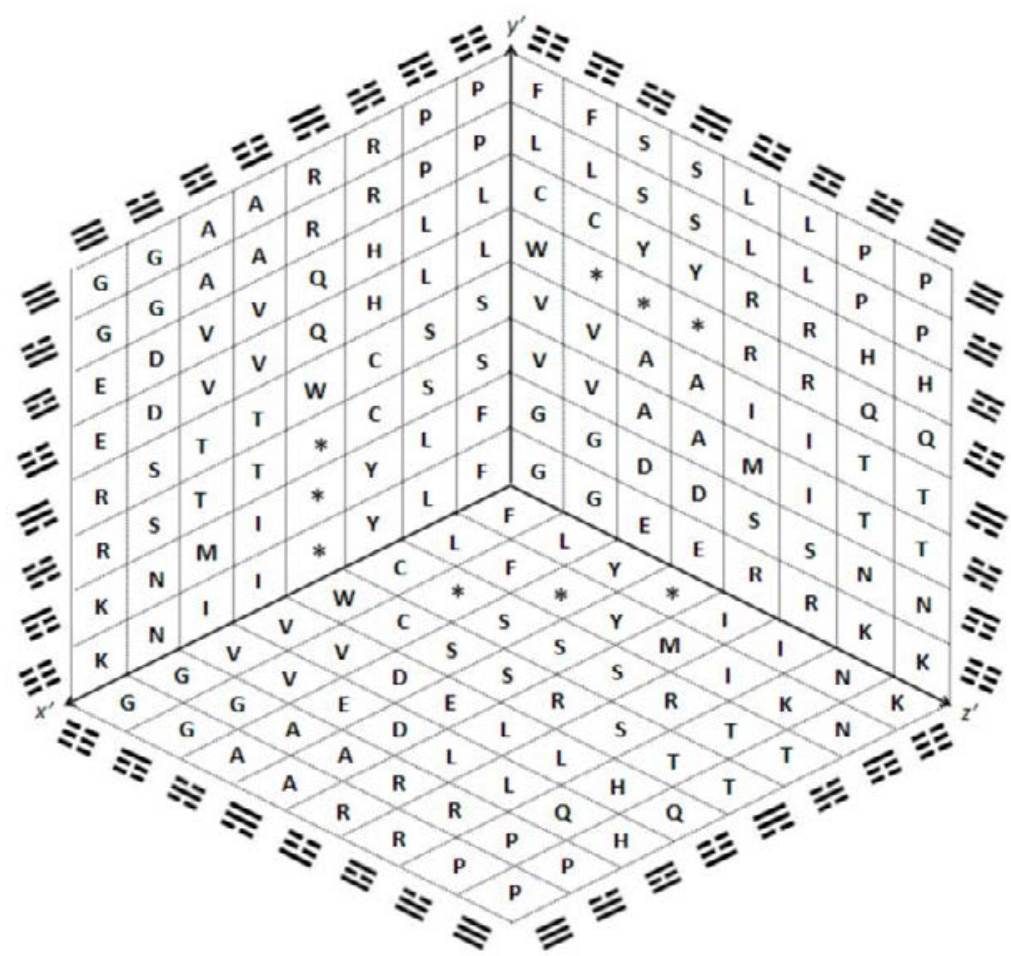

Figure 20: Inside of the three reciprocal Cartesian I Ching binary correlations of the genetic code as represented by its amino acids (see Appendix B).

If we now correlate the relative direction of the groups of codons according to their amino acids and/or functions, we obtain Figure 21 (for the standard correlation), and Figure 22 (for both the standard and the reciprocal correlations); and again, for these 3-D spatial versions were used, both the three standard correlations (Figure 21), and the reciprocals (Figure 22), of the Yin/Yang arrows shown in Figures 9 and 11.

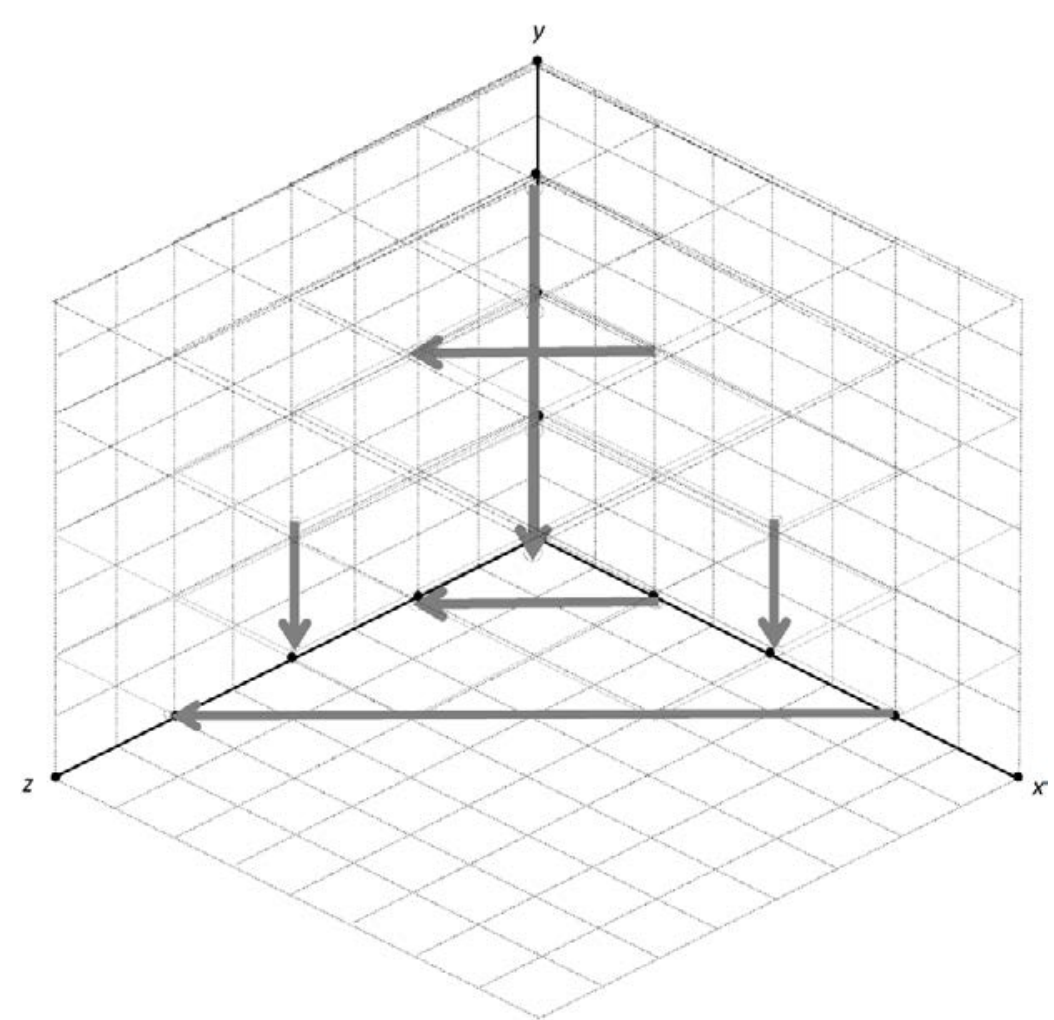

Figure 21: Yin/Yang direction of the groups of codons of the genetic code according to their resulting amino acids and/or functions (such as the start and stop codons), inside the standard side of the cube integrated by half of the codons within the cube, or by $64 \times 3=192$ codons. 
Citation: Castro-Chavez F (2014) File Compression and Expansion of the Genetic Code by the Use of the Yin/Yang Directions to Find its Sphered Cube. J Biodivers Biopros Dev 1: 112. doi:10.4172/2376-0214.1000112

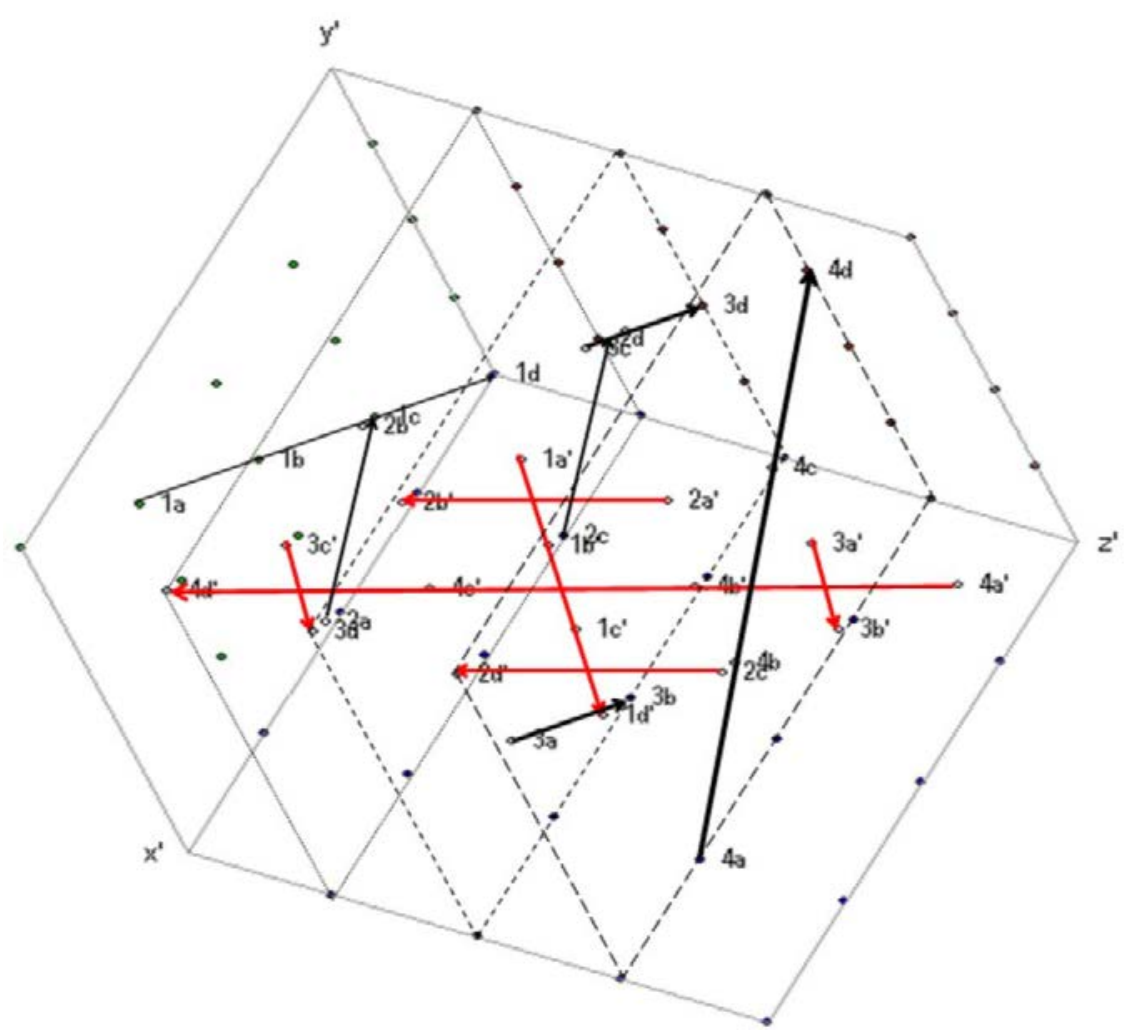

Figure 22: Yin/Yang direction of the groups of codons of the genetic code according to their resulting amino acids and/or functions (one starting and three ending codons), inside the complete $64 \times 6=384$ codon cube; this representation is integrated by every possible Cartesian I Ching standard binary correlation (in black) of the three properties of the nucleotides (hydrogen bonds, rings and tautomerism), and their three reciprocal binary correlations (in red).

Next, we are going to perform the 'sphering' of our genetic code's macro-cube to obtain our first meaningful spherical representation of it, both by codons (Figure 23), and amino acids (Figure 24). 
Increasing the level of complexity for our mentioned point of view as if standing inside the resulting cube, looking now to its two contiguous walls, and to its floor as if these were the three standard or normal correlations within the context shown by Figures 5, 6 and 10, we have the resulting Figure 17 for the codons, and Figure 18 for their resulting amino acids.

If we now look to the reciprocals of the previously defined as standard Cartesian I Ching genetic code correlations, we obtain Figures 19, 20, and Appendix B. In Appendix C we see the coordinates used to obtain those standard three correlations shown in Figures 17 and 18, as well as their respective reciprocals shown in Figures 19 and 20, within the pair of 3-D vector Cartesian graphics (axis $\mathrm{x}, \mathrm{y}, \mathrm{z}$ ) contained in the cube. The final product of this article will be a Sphered Cube for the genetic code (Figures 21 and 22).

If we now correlate the relative direction of the groups of codons according to their amino acids and/or functions, we obtain Figure 21 (for the standard correlation), and Figure 22 (for both the standard and the reciprocal correlations); and again, for these 3-D spatial versions were used, both the three standard correlations (Figure 21), and the reciprocals (Figure 22), of the Yin/Yang arrows shown in Figures 9 and 11.

Next, we are going to perform the 'sphering' of our genetic code's macro-cube to obtain our first meaningful spherical representation of it, both by codons (Figure 23), and amino acids (Figure 24).

Appendixes D show the net without words necessary to obtain the $8 \times 8 \times 6=384$ genetic code's cube.

When we obtained the Sphered Cube by transforming our genetic code's macro-cube into a sphere, we were surprised to realize that its resulting product was similar to the inverse reasoning of the 'cubedsphere', used initially in climatology for the subdivision of the earth [15-17], then in mechanics [18], in computational astrophysics

${ }^{4}$ Its $m d i$ file is available at: http://liveweb.archive.org/http://tinyurl.com/shcherbak
[19,20], in mathematics [21], physics, chemistry, hydrology [22,23], climatology, geology, meteorology [24], etc.; however, this article seems to be the first time that such a structure has been originated through an opposite reasoning: the 'Sphering' of the cube instead of the 'Cubing' of a sphere, being here applied to the genetic code and to biology in general; an early model was built to represent our planet by using a smaller, $6 \times 6=36$ grids times six [15], and a similar image to the one obtained here $(8 \times 8=64)$, but by using an inverse reasoning, was obtained by [24, in its p. 840].

The keen observations done earlier by shCherbak, who has worked several aspects of the mathematical balance of the genetic code, are that: "...one may assume that natural computing can exist as well... such a computing could be essence of exact gene processing and scrambling... If that is the case, some cell organelles should work as biocomputers... the genetic code is connected more closely to abstract notions of arithmetic than with notions of physics or chemistry" [25]. Through the findings presented in this article, these statements of shCherbak have been corroborated.

And, in a similar way to what we have seen in our introduction when presenting the word 'code', shCherbak earlier equated the stop codons with zero (Arabic, Mayan, and Computational), deeming the zero as the supreme arithmetical abstraction and concluding that its use by any alphabet, including the genetic code, is an indicator of what he called 'artificiality' (being such artificiality in this case, the intelligent design and purpose of the genetic code: to bring and to sustain life), while affirming that the decimalization of the genetic code could be a special case of the general computational power of genomics and its molecular machinery, observing that the main reason for the origin of a numerical system is to do mathematical calculations; shCherbak concluded that: "there is no way to write or read any gene when no code is available" [26]. ${ }^{4}$

As we mentioned earlier, the Cube and its Sphered Cube presented in this article can be used to compare sequences. Prompted by a reviewer

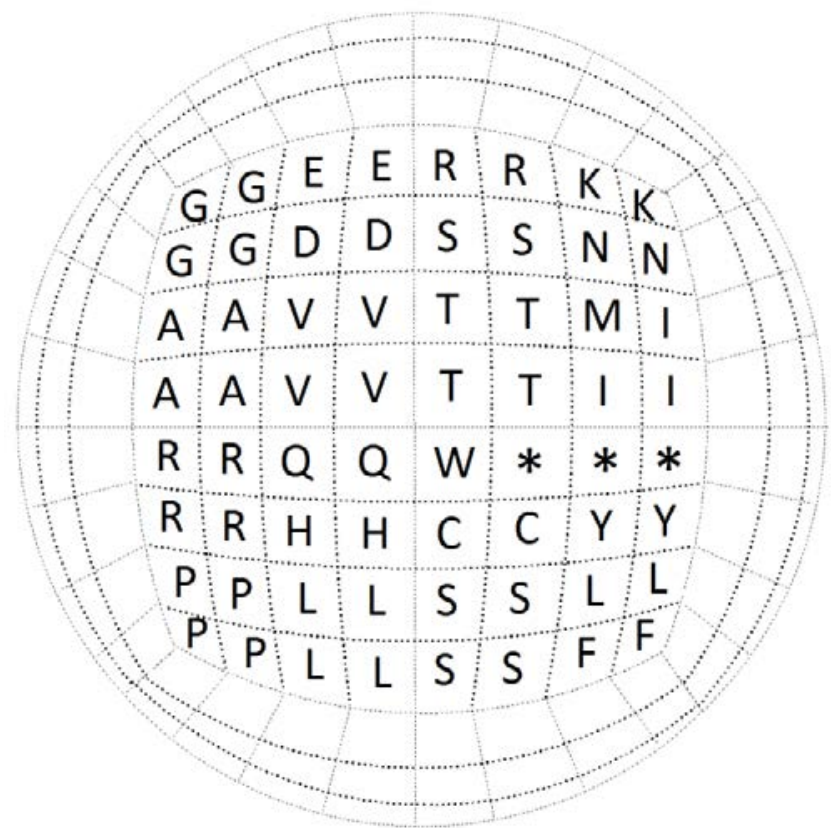

Figure 24: Spherical representation of the amino acids of the genetic code by transforming into a sphere the cube of Figures 14 to 22 (only one face is shown) 
Citation: Castro-Chavez F (2014) File Compression and Expansion of the Genetic Code by the Use of the Yin/Yang Directions to Find its Sphered Cube. J Biodivers Biopros Dev 1: 112. doi:10.4172/2376-0214.1000112
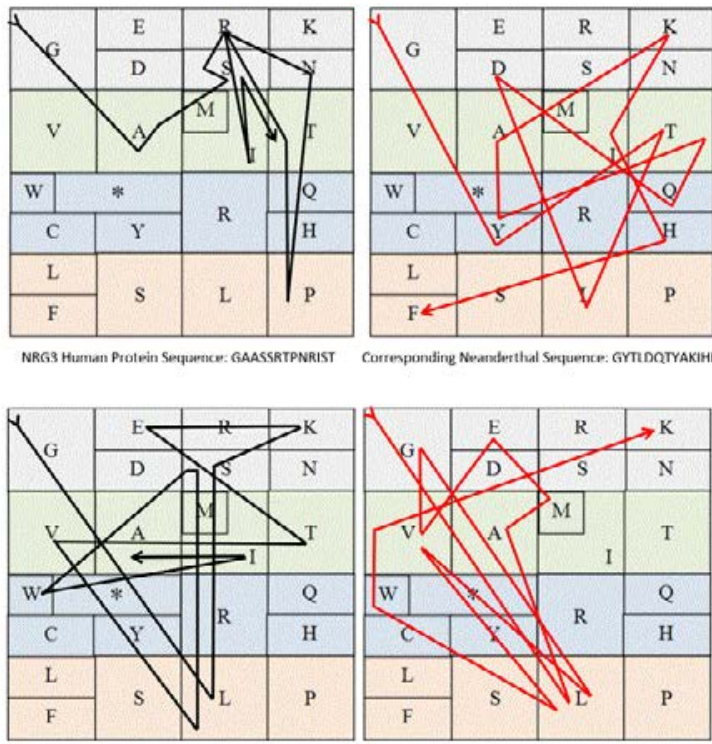

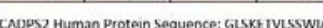
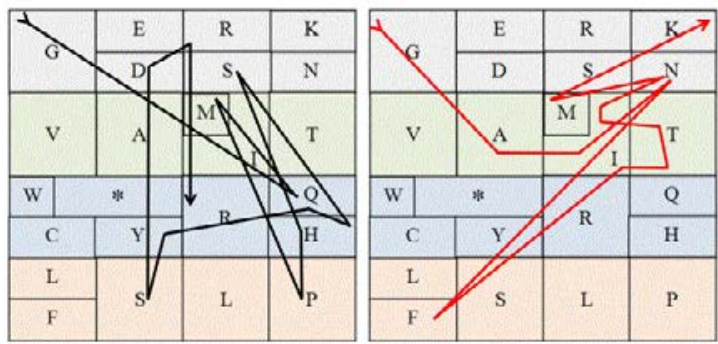
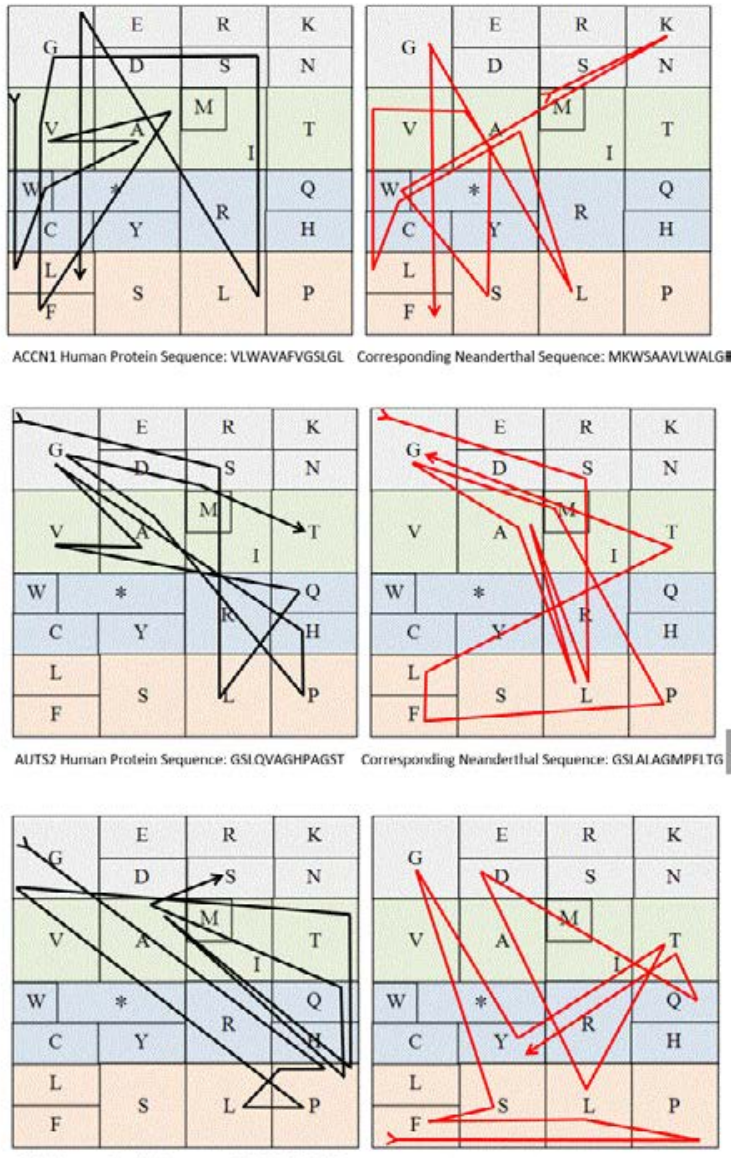

Figure 25: Differences in the comparison of six expressed gene-sequences between humans (left side in black arrows) and neanderthals (right side in red arrows). The I Ching's face of the genetic code used here corresponds to Figure 6. From top to bottom and from left to right, the six genes under consideration are: NRG3, ACCN1, CADPS2, AUTS2, DYRK1A and SOLH. Here, only one face of the cube is shown for a visual advantage; however, in practice, the full cube is to be used, just as if jumping from one face to another when an inner methionine appears, as indicated in [10]. The fractions of the expressed genes in Figure 25 correspond to Homo sapiens (black arrows), and are clearly differentiated from the ones belonging to $H$. neanderthalensis (red arrows). The strategy used was to find some expressed genes of interest in humans [Homo sapiens (taxid:9606)] as present in the GenBank: NRG3 [GAASSRTPNRIST, 27], ACCN1 (ASIC2) [VLWAVAFVGSLGL, 28], CADPS2 [GLSKETVLSSWIA, 27], AUTS2 [GSLQVAGHPAGST, 29], DYRK1A [GQMPHSHQYSDRR, 30] and SOLH [GPPLPGTPAPQAS, 31], and then to see for their equivalent translated portions in the Neanderthal genome by using the currently available Blast Protein (BlastP) Neanderthal database [Homo neanderthalensis (taxid:63221)]: 1 [GYTLDQTYAKIHF, 32], 2 [MKWSAAVLWALGF, 33], 3 [GLAMEVGLVLWVK, 33], 4 [GSLALAGMPFLTG, 32], 5 [GAINFITTIINMK, 33] and 6 [FPLFSGYTLDQTY, 33]. The genes were selected as vital for the normal working of the human brain, and due to the fact that they seem to be seriously altered, or mutated, within the genome of the Neanderthal $[34,35]$

and to demonstrate a practical application of our discovery, we will use here a compressed way of it by grouping its codons according to its resulting amino acids (Figure 25), where the matching sequenced genes can simultaneously run gene by gene within two cubes that belong to different organisms (in our example, Humans represented by the black arrows and Neanderthal by the red arrows), while pointing out to their differences by a resulting drawing.

More recently, while I was ready to resubmit this article, it was found that the patterns of expression are also very different between humans and neanderthals, highly differing in their methylation and deamination, a finding that may help explain why the expressed sequences of humans (the human amino acids) were extremely different (as shown in Figure 25), even corresponding, perhaps, to totally different proteins, when compared to neanderthals (the Neanderthal's amino acids). As an exercise, Figure 26 shows the differences on

${ }^{5} \mathrm{http}: / / c d n a . e v a . m p g . d e / n e a n d e r t a l$ ${ }^{6} \mathrm{http}: / /$ fdocc.ucoz.com/index/0-121 methylation/deamination between humans and 'a proxy' Neanderthal [36].

And, due to the fact that we are dealing with ancient sources of information, such as the I Ching and the Neanderthal's genome, in Appendix E I dare to present what ancient manuscripts in Hebrew (shown in the introduction), Aramaic and Greek, that are contained within the Bible have to say in relation to it. Otherwise, in order to analyze more in detail the currently full Neanderthal and Human sequences freely available through the Max Planck institute ${ }^{5}$, I will require of a greater computer power and memory space, as well as the development of a computational program with the Sphered Cube as its engine; for example, I performed earlier an unpublished analysis of some of the differences in the mitochondrial DNA between Humans and Neanderthal, ${ }^{6}$ however, the current study will be more graphically appealing.

Elsewhere, an example of a human polymorphism [9], and the comparison of the human genome with other organisms has been 
Citation: Castro-Chavez F (2014) File Compression and Expansion of the Genetic Code by the Use of the Yin/Yang Directions to Find its Sphered Cube. J Biodivers Biopros Dev 1: 112. doi:10.4172/2376-0214.1000112
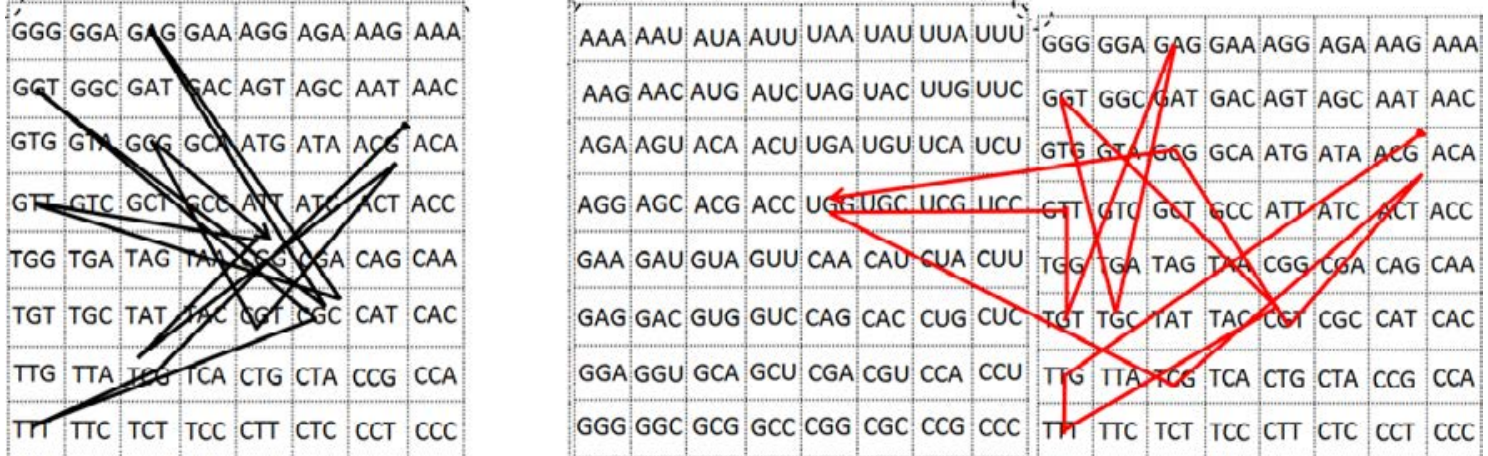

Figure 26: Exercise on the extreme differences in the patterns of methylation/deamination between modern humans (the reference genome, left side, black arrow), and a Neanderthal as 'proxy' (right side, red arrow). The I Ching's face of the human genetic code corresponds to Figure 6, while the one for the Neanderthal corresponds to a hybrid set of the two tables that are present at the right side of Figure 15 (the first one for the mRNA (U, Uracyl) and the second one for the DNA ( $T$, Thymine), respectively). The regulatory sequence that was experiencing methylation was taken from osteoblasts [36]

F

C
D
A

2
6
18
54
162

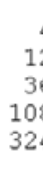

8
24
72
216
648

\begin{tabular}{r|rrrrr|}
$5+$ & $11-$ & $21+$ & $43-$ & $85+$ & $171-$ \\
16 & -32 & 64 & 128 & 256 & 512 \\
48 & 96 & 192 & 384 & 768 & \\
144 & 288 & 576 & & & \\
432 & 864 & & & \\
\hline
\end{tabular}

Figure 27: Pythagorean music series; multiples of the genetic code of 64 codons are in the big horizontal rectangle at the right side, and if multiplied by ten, potential multiples of it are also in the intermittent vertical rectangle located at its left side, while inside of them, the 'symmetry' of the actual numbers that appear within the $64 \times 6=384$ Sphered Cube of the genetic code is shown (the number 32 located at the left side is included, if and when multiplied by 10 , as in: $32 \times 10=320=5 \times 64)$.

presented [9,37], as well as one molecular application of the genetic code in 3-D to differentiate the start from non-start Methionines within proteins [10].

Also, and apart of exploring the 3-D properties of the genetic code, cell cultures in 3-D have been recently used by the author of this article in an attempt to simulate the current conditions of living tissues through the modeling of the origin and attenuation of atherosclerosis [38] in human osteogenic trans-differentiating vascular smooth muscle cells (VSMC $)$. We saw that Lyso-phosphatidylcholine (LPC) at physiological concentrations $(10 \mathrm{~nm})$, instead of the entire Low Density Lipoprotein (LDL) or 'bad cholesterol', seemed to have been the main responsible for the development of calcification in atherosclerosis [3941], being this a defensive response of the arterial muscular cells against the detergent-like effects of the LPC, a mechanism for those cells to protect themselves.

The optimization of the 3-D cell culture methodology for atherosclerosis required more than two years; however, reference [42], not only added the LPC that was successfully demonstrated by us [39], while using my methodologies and materials with no credits, but also ruined our experimental model by adding two extra, non-necessary and non-physiological reagents: $\beta$-glycerophosphate $(7.5 \mathrm{mM})$ and ascorbic acid $(50 \mu \mathrm{g} / \mathrm{ml})$, being these additions reflected in their work by the retention of hydroxyapatite within the $\mathrm{VSMC}_{\mathrm{s}}$ of their 3-D cluster (seen at the end of their third composite illustration), instead of being normally secreted, as it was shown in all of our Figures [38].

Our original work [38] demonstrates that a 3-D perspective is highly useful in biomedical research, not only for its 3-D cell cultures, but also for the current study of the genetic code in 3-D as shown here.
Tidjani Negadi, a dedicated researcher of the genetic code, has been able to find numerous instances of the number 384 within the genetic code, a number here obtained through our I Ching cube $(64 \times 6=384)$; Negadi presents at least 15 calculations to obtain the number 384 within the genetic code:

1) $360+\operatorname{tau}(360)=360+24=384$ [43] (number equal to the number of atoms in the 20 amino acids, side-chain and block [44], as well as the total number of nucleotides in the 64 RNA-codons and in the 64 DNA codons [45]),

2) $(73+11)+300=84+300=384[43]$,

3) $(99+74+7)+(73+41+11+20+35)+\sigma(360)=180+204=384[43]$,

4) $360+(5+5+5)+9=384[43]$,

5) $2 \times 192=384[43,45]$,

6) $(3412 / 2 x)-1255-67=384$ (from the irregular L- and D- (integer) tetrahedron, "a warehouse of biological information") [43],

7) $192+192=384$ [45] (The mean of the four pairs equal 192, the total number of nucleobases in the 64 codons, but also the total number of codons in DNA and RNA (2×64) [46]),

8) $768 / 2=384[46]$,

9) $\mathrm{phi}^{(2)}(\mathrm{psi})=384[46]$,

10) psi upper bar ${ }_{(0,1,0,0)}(\mathrm{psi})=$ psi upper $\operatorname{bar}_{(0,0,3,0)}(\mathrm{psi})=384[46]$,

11) Writing $3276+676$ and introducing the identity " $-384+384$ " (384=384 or " $384-384=0$ "), we get $2892+1060$ which is the "partition of nucleon-numbers between the four-codon set and the non-four codon set" [46],

12) $\operatorname{phi}(1152)=384[46]$,

13) $313+71=384=204+(9 \times 20)$,

14) Filatov [47] also "established a nucleon number balance in two pairs of faces $628+627=626+629=1255$. Now computing the atom number in the amino acids in the two pairs of faces, we find 108+97=205 and 104+99=203 (without the side-chains) or 198+187=385 and $194+189=383$ (including the side-chains). These are near balances and the average of the two pairs gives 204 and 384 atoms, respectively, for the correct atom number. Now from our numbers 139 (34th prime) and 1304, we could take the sum of the prime factors and the prime indices 
to get 173 and 210 with sum 383. This is the nucleon number in one of the two pairs of faces mentioned above ... and we could reach 384 by just adding the Omega-function of the prime number 139 which is simply 1. Also, by re-arranging the terms we have $(139+34+1+6)=180$ and $(163+38+3)=204$. The first number is the total atom number in the 20 blocks and second is the atom number in the 20 side-chains". So, concluding the last computation, we have $(139+34+1+6)+(163+38+3$ )$=384=180+204$ [The points 13 and 14 were found in Negadi's blog].

15) Plus, a music related one: "The numbers 192 and 384 seem very important numbers" [Plato did choose 192 as a starting point while Timaeus the Locrian did choose 384] "...they are basic numbers in the Pythagorean music tuning system” [45] (also see [44]).

Figure 27 shows how both our 384-grid Cube and Sphered Cube representation of the genetic code can be compared to the Pythagorean music series.

Using only proportions of 2 and 3 ( \pm mean by $1 / 3$, in row $F$ ), the frequency relationships seen in Figure 27, when applied to the building-up of the I Ching genetic code are: $64,128,192,256$, and 384; however, the I Ching's successive number 320 that appears between 256 and 384 is not present; the numbers that are actually present, in the current context are: $64 \times 1=64,64 \times 2=128,64 \times 3=192,64 \times 4=256$, [the next consecutive one, $64 \times 5=320$, is absent in the Pythagorean music system], and $64 \times 6=384$. Additional multiples of 64 that are seen in the Pythagorean musical scale are: $64 \times 8=512,64 \times 9=576$ and $64 \times 12=768$.

Notably, if the numbers within the left side column (headed by $11-$ in the row F) are multiplied by 10, all of them became also multiples of 64 , including the previously missing $64 \times 5=320$, plus $64 \times 15=960$, $64 \times 45=2880$, and $64 \times 135=8640$.

Regarding such discrepancy seen in lines $\mathrm{C}$ and $\mathrm{E}$ (and even $\mathrm{B}$ ) of the Pythagorean music series, Ray Tomes observes: " $C$ is incorrectly related to $E$ and $B$... as Galilei observed, $C$ and $E$ want to be in the proportion 4:5 (which is 64:80) and we have 64:81 so it just misses... The equitempered scale is designed around the ratio 2 because each semitone is a ratio of 1 to the twelfth root of 2 . As it turns out this accommodates ratios of 3 almost perfectly, which is of course why it was chosen... I invented a system which I call AJI for Automatic Just Intonation. I realised [sic] that an electronic keyboard doesn't have to make compromises when selecting frequencies as there is no reason that a single key cannot produce different frequencies depending on the circumstances..." In our case, as mentioned earlier, we multiplied by ten the whole column 11- to make it 'fit' the pattern of our design, and it worked, providing us with an artificially 'perfect' symmetry, as seen in Figure 27.

16) In our case, the number 384 was also obtained by counting the individual binary components within any of the I Ching's genetic code tables (Figures 5, 6, 10), where we see that each cell is composed by a trigram from the $\boldsymbol{y}$ axis, over which a trigram from the $\boldsymbol{x}$ axis is added, integrating an hexagram, so when multiplying one hexagram by the totality of the cells, we also obtain the number $384: 6 \times 64=384$.

Finally, and as the last project of my free programming edX Harvard University class (cs50x), I decided to put motion to my earlier work to illustrate the complementary pairing by rows of the basic structure of the Figure 5 of this article, which is similar, but not identical, to the first Table (T.1) of Figure 1 of my previously related publication [10]. The project in its final form can be seen at: http://www.youtube.com/ watch?v=0aacCShsmWo, coupled to an explanation of it. The basic 8

${ }^{7}$ Class CS184.1x Foundations of Computer Graphics, imparted by Ramamoorthi, from U.C. Berkeley (free at edX). sprites and 9 scripts used to develop the animation for this video can be downloaded at its M.I.T. 'source code':

http://scratch.mit.edu/projects/fdocc/3226378 Our current experimental lab work dealing with 3-D cubic cylinders and crystallized geometries can also be seen at: http://youtu.be/oYd96rj_51Q

\section{Conclusions}

Biodiversity on earth is based on the flexibility and plasticity of the genetic code. This is just the start of studies demonstrating the enormous plasticity of the genetic code, being its current representations and its future possible ones like a metaphorical reflection of the real plasticity contained within living organisms [10], being this the reason for their great variability and adaptation as seen in the exuberant biodiversity that surrounds us.

We also showed here the reverse engineering in 2-D of a previously obtained functional tetrahedron in 3-D [10]. The resulting products were a square (Figure 1) and a circle (Figure 2). We also folded a 3-D double genetic code representation composed by a Stella Octangula (Figures 3 and 4) found earlier [10].

The rotation seen in Figure 9 from row 1 to row 4 can also be perceived as evocative of the actual helical rotation that is seen in the double helix [14]. The two circular and compressed representations of the genetic code with the stop codon at the centre that are shown in Figure 12, if they were rotating through a pin at their centre, while an external arrow were pointing at their respective codons, if it were stopped at a line between two of these portions, it will go then to the stop codons located at its centre.

The inclined rotational axis of 45 degrees shown in Figures 14-16 (represented there by the intermittent circles, their net can be seen in Appendix D), remind us of the inclined orbital axis of the earth; these diagonals of computational geometry within a cube are deemed to be located either as a $\pi / 4$ or a $3 \pi / 4$, depending if the relative view is from left to right or vice versa [48-50] shows the software used to develop (Figure 22).

The zipping or compression of the codons by groups, both in the 3-D and in 2-D representations of the genetic code discussed here may increase the speed of our comparison of sequences, as well as our explorations of the genetic code within curved spaces, spaces studied in my classes related to the foundations of computer graphics; ${ }^{7}$ i.e., the resulting cubed-sphere may be useful to compare sequences, either from wildlife or from humans in an appealing visually graphic way, noticing also that the file expansion shown here is not the same as the unzipping of the computer files, being this the product of the restoration to the same size of the original file as it was before, while the file expansion shown here results in the increase of informational content.

Here it was also shown that human genes translated from the brain and from a promoter in osteoblasts, are compared to their corresponding Neanderthal sequences to show their differences and to demonstrate the use of the I Ching's genetic code in 3-D (Figures 25 and 26). After these findings, we can declare with confidence that the oldest known representation of the Genetic Code is the binary I Ching, also known as the Book of Changes or Book of Mutations, corresponding these changes to biological changes or mutations, a book preserved by the Chinese, but evidently being older than them, a survivor of the burning of ancient documents by the Emperor Chi (also known as Qi).

In relation to this and to my previous works, a recent article declared: "Those two properties (ie, symmetry and periodicity) act as 
the harmony between the chosen geometry and the biological reality. Graphical representation of DNA sequences based on mono, di, trinucleotides, etc. need to consider this harmony. Otherwise, it would merely be an instance of displaying the nucleotides (eg, mononucleotide, dinucleotide, codon) which have little biological sense" [51]; with the current work, the corroboration of such observations is advanced.

A recent article [52], making also reference to one of my earliest works related on the 2 -D circular genetic code, when alluding to "the palindromes of the genetic code", declared: "that some researchers have tried to restrict at peculiar symmetries"; my answer is that in order to learn from the continuous wisdom manifested within the genetic code, certainly the less limited our analyses are, the best their output will be; I strive to encourage every student and researcher of the genetic code to explore the fullness of its possibilities without dismay.

Once more, the enormous plasticity that we see in the study of the genetic code is a reflection of the real plasticity contained within living organisms, being this the ultimate reason for their great variability and adaptation. The great variability seen in nature can better be understood by studying its source, the genetic code; for example, in my earlier studies $[8,9]$ of the 2-D classic circular genetic code [5], I recently realized that the Hydroxyl amino acids, those ones that are phosphorilatable in order to activate the dormant enzymes, are also located in a balancing way within quadrant 1 (4 Ser+2 Tyr), and quadrant 3 ( $2 \mathrm{Ser}+4 \mathrm{Thr})$.

The use of the Yin/Yang (Yin and Yang) in this article is within the context of the Genetic Code in 3-D, something apparently known and fully represented since a long time; i.e., in the I Ching or Book of Changes; however, the use of this concept is not new within medicine and molecular biology; a few set of examples from the numerous found within PubMed (currently 500 references), are given at [53-85].

Here, by grouping the reiterations or "redundancies" of the genetic code, reiterations apparently designed to preserve its functionality while allowing the adaptability of living organisms, a more detailed picture appeared, both in 2-D and in 3-D, when comparing the Cartesian binary combinations of the properties of nucleotides, then the directions of the Yin and of the Yang arrows suddenly appeared. It is precisely this reiterated redundancy of the genetic code, the basis for its 'file compression' in bioinformatics and biodiversity; additionally, it was shown that the number 384 , obtained in this article by multiplying $64 \times 6$ within all the possible binary comparisons of the genetic code derived from the I Ching, has also been found within the mathematics derived from the molecules that integrate the genetic code, as seen above when our current work is compared with that of Negadi [43,45-46], and others $[44,47]$.

On concluding, I may say that the main findings of this work are: That the Yin/Yang's genetic code directions are similar to those that are presented by the actual separate DNA strands in relation to their autoreplicating new strands, and/or in relation to their new RNA products, specially by the plus strand at the moment of transcription for the last example. Also including the minus strand, and its smaller replicating segments known as the Okazaki fragments for the DNA autoreplication. The findings presented here can help in bioinformatics; i.e., by locating at the center of a computer program the genetic code in its cubic or spherical form, not only to compare sequences in an attractive or aesthetic way, but also to provide didactic illustrations of these proceedings.

\section{Acknowledgments}

I thank God for giving me the time and strength to do this work, and to my wife Tracy L. Duncan for her unconditional support: to Reid and Sheryl McNally, Stephen and Brenda Sparks, Cathy Keener, Eliezer Mendelssohn, Fernando Paularena, Glenn Lewis, Lynn D. Wills, David J. Lewis, Margina Huq, Sheldon Yoder, Bruno Bazan, Zachary Greenbauer, Chris Caldwell, Daniel Garcia, Mark Skipski, Maria Lantsman, Olivia Nguyen, and to the rest of my coworkers that make all the daily work enjoyable; and also to my parents, sisters, nephews, to the inlaws, and to my students Ana Baleva and Karen Scarbrough, as well as to my spiritual and physical families and friends. This manuscript was supported in part by the NIH grant T32 HL-07812.

The Appendixes A, B, C, D, and E for this article can be found at: http://fdocc ucoz.com/index/0-122 (saved at: http://liveweb.archive.org/web/20140617155918/ http://fdocc.ucoz.com/index/0-122

\section{References}

1. Bishop D (2003) Introduction to cryptography with Java applets. Jones \& Bartlett Learning 16-17.

2. Leonhard W (2013) Windows 8.1 All-in-One for Dummies.Wiley, 1056.

3. Nirenberg MW (1965) 64 triplets and complementary triplets. Unpublished laboratory note.

4. Crick FH (1967) The Croonian lecture, 1966. The genetic code. Proc R Soc Lond B Biol Sci 167: 331-347.

5. Bresch C, Hausmann R (1972) Der genetische code. In: Bresch C, Hausmann R, eds. Klassische und Molekulare Genetik. Springer (Berlin) 243-278.

6. Fujiomoto M (1987) Tetrahedral codon stereo-table. U.S. Patent 4,702,704, 9 p

7. Keppleri I (1619) Harmonices mundi. Johannes Plancus (Austria)

8. Castro-Chavez $F(2010)$ The rules of variation: amino acid exchange according to the rotating circular genetic code. J Theor Biol 264: 711-721.

9. Castro-Chavez F (2012) The rules of variation expanded, implications for the research on compatible genomics. Biosemiotics 5:121-145.

10. Castro-Chavez F (2012) Defragged binary I Ching genetic code chromosomes compared to Nirenberg's and transformed into rotating $2 \mathrm{D}$ circles and squares and into a 3D 100\% symmetrical tetrahedron coupled to a functional one to discern start from non-start methionines through a stella octangula. JPSCB 1 $: 1-24$

11. Castro-Chavez F (2012) A Tetrahedral Representation of the Genetic Code Emphasizing Aspects of Symmetry. BIOcomplexity 2012: 1-6.

12. Castro-Chavez F (2011) The Quantum Workings of the Rotating 64-Grid Genetic Code. Neuroquantology 9: 728-746.

13. Swanson R (1984) A unifying concept for the amino acid code. Bull Math Biol 46: $187-203$

14. WATSON JD, CRICK FH (1953) Molecular structure of nucleic acids; a structure for deoxyribose nucleic acid. Nature 171: 737-738.

15. Sadourny R (1972) Conservative finite-difference approximations of the primitive equations on quasi-uniform spherical grids. Mon Weather Rev 100:136-144.

16. Rancic M, Purser J, Messinger F (1996) A global shallow water model using an expanded spherical cube: Gnomonic versus conformal coordinates. Q J Roy Meteor Soc 122:959-982.

17. Purser J, Rancic M (1998) Smooth quasi-homogeneous gridding of the sphere. Q J Roy Meteor Soc 124:637-647.

18. Koldoba AV, Romanova MM, Ustyugova GV, Lovelace RVE (2002) Threedimensional magnetohydrodynamic simulations of accretion to an inclined rotator: The "cubed sphere" method. ApJ 576 : L53-L56.

19. Romanova MM, Ustyugova GV, Koldoba AV, Wick JV, Lovelace RVE (2003) Three-dimensional simulations of disk accretion to an inclined dipole. I. Magnetospheric flows at different T. ApJ 595 : 1009-1031.

20. Fragile PC, Lindner CC, Anninos P, Salmonson JD (2009) Application of the cubed-sphere grid to tilted black hole accretion disks. ApJ 691:482-494

21. Ronchi C, lacono R, Paolucci P (1996) The "Cubed-Sphere:" a new method fo the solution of partial differential equations in spherical geometry. J Computat Phys $124: 93-114$

22. Cheruvua V, Nairb RD, Tufoa HM (2007) A spectral finite volume transport scheme on the cubed-sphere. Appl Numer Math $57: 1021-1032$. 
Citation: Castro-Chavez F (2014) File Compression and Expansion of the Genetic Code by the Use of the Yin/Yang Directions to Find its Sphered Cube. J Biodivers Biopros Dev 1: 112. doi:10.4172/2376-0214.1000112

Page 16 of 17

23. Chen CG, Xiao F, Li XL, Yang Y (2011) A multi-moment transport model on cubed-sphere grid. Int J Numer Meth FI 67 : 1993-2014.

24. Washington WM, Buja L, Craig A (2009) The computational future for climate and Earth system models: on the path to petaflop and beyond. Philos Trans A Math Phys Eng Sci 367: 833-846.

25. shCherbak VI (2003) Arithmetic inside the universal genetic code. Biosystems 70: 187-209.

26. shCherbak $\vee(2008)$ The arithmetical origin of the genetic code. In: Barbieri, Marcello (Ed.) The Codes of Life. Springer (Berlin). 153-188.

27. Strausberg RL, Feingold EA, Grouse LH, Derge JG, Klausner RD, et al. (2002) Generation and initial analysis of more than 15,000 full-length human and mouse cDNA sequences. Proc Natl Acad Sci U S A 99: 16899-16903.

28. Gregersen N, Dahl HA, Buttenschøn HN, Nyegaard M, Hedemand A, et al (2012) A genome-wide study of panic disorder suggests the amiloride-sensitive cation channel 1 as a candidate gene. Eur J Hum Genet 20: 84-90.

29. Beunders G, Voorhoeve E, Golzio C, Pardo LM, Rosenfeld JA, et al. (2013) Exonic deletions in AUTS2 cause a syndromic form of intellectual disability and suggest a critical role for the $C$ terminus. Am J Hum Genet 92: 210-220.

30. Guimerá J, Casas C, Pucharcòs C, Solans A, Domènech A, et al. (1996) A human homologue of Drosophila minibrain (MNB) is expressed in the neuronal regions affected in Down syndrome and maps to the critical region. Hum Mo Genet 5: 1305-1310.

31. Kamei M, Webb GC, Young IG, Campbell HD (1998) SOLH, a human homologue of the Drosophila melanogaster small optic lobes gene is a member of the calpain and zinc-finger gene families and maps to human chromosome 16 13.3 near CATM (cataract with microphthalmia). Genomics 51 : 197-206.

32. Briggs AW, Good JM, Green RE, Krause J, Maricic T, et al. (2009) Targeted retrieval and analysis of five Neandertal mtDNA genomes. Science 325: 318321.

33. Green RE, Malaspinas AS, Krause J, Briggs AW, Johnson PL, et al. (2008) A complete Neandertal mitochondrial genome sequence determined by highthroughput sequencing. Cell 134: 416-426.

34. Green RE, Krause J, Briggs AW, Maricic T, Stenzel U, et al. (2010) A draft sequence of the Neandertal genome. Science 328: 710-722.

35. Gibbons A (2010) Paleogenetics. Close encounters of the prehistoric kind Science 328: 680-684.

36. Gokhman D, Lavi E, Prüfer K, Fraga MF, Riancho JA, et al. (2014) Reconstructing the DNA methylation maps of the Neandertal and the Denisovan. Science 344: 523-527.

37. Castro-Chavez F (2011) Most Used Codons per Amino Acid and per Genome in the Code of Man Compared to Other Organisms According to the Rotating Circular Genetic Code. Neuroquantology 9.

38. Castro-Chavez F, Vickers KC, Lee JS, Tung CH, Morrisett JD (2013) Effect of Lyso-phosphatidylcholine and schnurri-3 on osteogenic transdifferentiation of vascular smooth muscle cells to calcifying vascular cells in 3D culture. Biochim Biophys Acta 1830 : 3828-3834

39. Vickers KC, Castro-Chavez F, Morrisett JD (2010) Lyso-phosphatidylcholine induces osteogenic gene expression and phenotype in vascular smooth muscle cells. Atherosclerosis 211: 122-129.

40. Castro-Chavez F, Morrisett JD (2011) Osteogenic transdifferentiation of vascular smooth muscle cells to calcifying vascular cells in 3D culture: enhancement by lyso-phosphatidylcholine and attenuation by Schnurri-3. Poster 1108-116, ACC 11, J Am Coll Cardiol 57: E1548.

41. Castro-Chavez F, Lee JS, Tung CH, Morrisett JD (2011) Osteogenic transdifferentiation of vascular smooth muscle cells in 3D, detecting hydroxyapatite with a specific probe derived from the alpha region of osteocalcin, Rolanette and Berdon Lawrence Bone Disease Program of Texas Scientific Retreat, Marriott Medical Center Hotel. Baylor College of Medicine and MD Anderson Cancer Center, p3.

42. Lee JS, Morrisett JD, Tung CH (2012) Detection of hydroxyapatite in calcified cardiovascular tissues. Atherosclerosis 224: 340-347.

43. Negadi T (2012) the irregular (integer) tetrahedron as a warehouse of biological information. Symm Cult Sci 23(3-4):403-426.

44. Rakocevic MM (2013) Harmonic mean as a determinant of the genetic code arXiv:1305.5103v4 [q-bio.OT], 20 p.
45. Negadi T (2011) The multiplet structure of the genetic code, from one and small number. Neuroquantology $9: 379-384$.

46. Negadi T(2011)A "quantum-like" approach to the genetic code. Neuroquantology $9: 785-798$

47. Filatov $F$ (2009) A molecular mass gradient is the key parameter of the genetic code organization. arXiv:0907.3537v1 [q-bio.OT], 9 p.

48. Mukkamala P, Palvolgyi D (2012) Drawing cubic graphs with the four basic slopes. Lect Notes Comput Sc (7034) 254-265.

49. Jeon G, Fang Y, Lee K, Kang K, Jeong J (2012) Improved low-complexity interpolation algorithm for deinterlacing. OJEEE 2 : 259-263.

50. Doka G (2002) Life Cycle Assessment of municipal solid waste incineration with the PECK technology ARGE PECK (Zurich) $80 \mathrm{p}$

51. Bari AT, Reaz MR, Islam AK, Choi HJ, Jeong BS (2013) Effective Encoding for DNA Sequence Visualization Based on Nucleotide's Ring Structure. Evol Bioinform Online 9: 251-261.

52. Godina-Nava JJ (2013) Horizontal symmetry in the algebraic approach of genetic code. arXiv:1302.3289v1 [physics.gen-ph], $20 \mathrm{p}$.

53. Mango R, Predazzi IM, Romeo F, Novelli G (2011) LOX-1/LOXIN: the Yin/Yang of atheroscleorosis. Cardiovasc Drugs Ther 25: 489-494.

54. Rissman EF (2008) Roles of oestrogen receptors alpha and beta in behavioural neuroendocrinology: beyond Yin/Yang. J Neuroendocrinol 20: 873-879.

55. Weber DS, Griendling KK (2003) The Yin/Yang of superoxide dismutase mimetics: potential cardiovascular therapies? Br J Pharmacol 139: 1059-1060.

56. Mann DL (2002) The Yin/Yang of innate stress responses in the heart. Cold Spring Harb Symp Quant Biol 67: 363-370.

57. Weissmann G, Goldstein I, Hoffstein S, Chauvet G, Robineaux R (1975) Yin/Yang modulation of lysosomal enzyme release from polymorphonuclea leukocytes by cyclic nucleotides. Ann N Y Acad Sci 256: 222-232.

58. Clark CE, Liu Y, Cooper HM (2014) The Yin and Yang of Wnt/Ryk axon guidance in development and regeneration. Sci China Life Sci 57: 366-371.

59. Wu XS, Wu LG (2014) The yin and yang of calcium effects on synaptic vesicle endocytosis. J Neurosci 34: 2652-2659.

60. Martin DS, Grocott MP (2013) III. Oxygen therapy in anaesthesia: the yin and yang of O2. Br J Anaesth 111: 867-871.

61. Olsen LF, Issinger OG, Guerra B (2013) The Yin and Yang of redox regulation. Redox Rep 18: 245-252.

62. Nie J, Han X, Shi Y (2013) SAD-A and AMPK kinases: the "yin and yang" regulators of $\mathrm{mTORC} 1$ signaling in pancreatic $\hat{~}^{2}$ cells. Cell Cycle 12: 3366 3369

63. Martins-Green M (2013) The Yin and Yang of Integrin Function in ReEpithelialization During Wound Healing. Adv Wound Care (New Rochelle) 2 $75-80$

64. Shiekhattar R (2013) The Yin and Yang of enhancer-like RNAs. EMBO J 32 2533-2534.

65. Han HW, Ohn JH, Moon J, Kim JH (2013) Yin and Yang of disease genes and death genes between reciprocally scale-free biological networks. Nucleic Acids Res 41: 9209-9217.

66. Pradere JP, Dapito DH, Schwabe RF (2013) The Yin and Yang of Toll-like receptors in cancer. Oncogene

67. Tobin DM, Ramakrishnan L (2013) TB: the Yin and Yang of lipid mediators. Curr Opin Pharmacol 13: 641-645.

68. Stange DE, Clevers H (2013) Concise review: the yin and yang of intestinal (cancer) stem cells and their progenitors. Stem Cells 31: 2287-2295.

69. Edgerton DS, Cherrington AD (2013) Glucagon's yin and yang effects on hepatic glucose production. Nat Med 19: 674-675.

70. Axelrad MD, Budagov T, Atzmon G (2013) Telomere length and telomerase activity; a Yin and Yang of cell senescence. J Vis Exp : e50246.

71. Munro CA (2013) Chitin and glucan, the yin and yang of the fungal cell wall, implications for antifungal drug discovery and therapy. Adv Appl Microbiol 83 $145-172$. 
Citation: Castro-Chavez F (2014) File Compression and Expansion of the Genetic Code by the Use of the Yin/Yang Directions to Find its Sphered Cube. J Biodivers Biopros Dev 1: 112. doi:10.4172/2376-0214.1000112

72. Alvarez AF, Rodriguez C, Georgellis D (2013) Ubiquinone and menaquinone electron carriers represent the yin and yang in the redox regulation of the ArcB sensor kinase. J Bacteriol 195: 3054-3061.

73. Tan M, Wang M, Zhou XL, Yan W, Eriani G, et al. (2013) The Yin and Yang of tRNA: proper binding of acceptor end determines the catalytic balance of editing and aminoacylation. Nucleic Acids Res 41: 5513-5523.

74. So AY, Zhao JL, Baltimore D (2013) The Yin and Yang of microRNAs: leukemia and immunity. Immunol Rev 253: 129-145.

75. Jiménez J, Truman AW, Menoyo S, Kron SJ, Clotet J (2013) The yin and yang of cyclin control by nutrients. Cell Cycle 12: 865-866.

76. Zhang EY, Kong KF, Altman A (2013) The yin and yang of protein kinase C-theta (PKCî.): a novel drug target for selective immunosuppression. Adv Pharmacol 66: 267-312.

77. Burke AJ, Sullivan FJ, Giles FJ, Glynn SA (2013) The yin and yang of nitric oxide in cancer progression. Carcinogenesis 34: 503-512.

78. Vij N, Downey GP (2013) The yin and yang of cystic fibrosis transmembrane conductance regulator function: implications for chronic lung disease. Am J Respir Crit Care Med 187: 120-122.
79. Vasquez KM, Wang G (2013) The yin and yang of repair mechanisms in DNA structure-induced genetic instability. Mutat Res 743-744: 118-31.

80. Kubli DA, Gustafsson ÅB (2012) Mitochondria and mitophagy: the yin and yang of cell death control. Circ Res 111: 1208-1221.

81. Weinberg A, Jin G, Sieg S, McCormick TS (2012) The yin and yang of human Beta-defensins in health and disease. Front Immunol 3: 294.

82. Hein GJ, Baker C, Hsieh J, Farr S, Adeli K (2013) GLP-1 and GLP-2 as yin and yang of intestinal lipoprotein production: evidence for predominance of GLP-2 stimulated postprandial lipemia in normal and insulin-resistant states. Diabetes 62 : 373-381.

83. Adams EJ, Luoma AM (2012) The yin and yang of CD1d recognition. Nat Immunol 13: 814-815.

84. Sladek FM (2012) The yin and yang of proliferation and differentiation: cyclin D1 inhibits differentiation factors ChREBP and HNF4Ît. Cell Cycle 11: 31563157.

85. Hou J (2012) The yin and yang of claudin-14 function in human diseases. Ann N Y Acad Sci 1258: 185-190. 